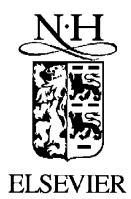

\title{
The rewards to meeting or beating earnings expectations 光 $^{2}$
}

\author{
Eli Bartov ${ }^{\mathrm{a}}$, Dan Givoly ${ }^{\mathrm{b}}$, Carla Hayn ${ }^{\mathrm{c}, *}$ \\ ${ }^{a}$ Stern School of Business, New York University, New York, NY 10012-1118, USA \\ ${ }^{\mathrm{b}}$ Graduate School of Management, University of California at Irvine, Irvine, CA 92697-3125, USA \\ ${ }^{\mathrm{c}}$ The Anderson Graduate School of Management, University of California at Los Angeles, Los Angeles, \\ CA 90095-1481, USA
}

Received 2 March 2001; received in revised form 5 December 2001

\begin{abstract}
This paper finds that firms that meet or beat current analysts' earnings expectations (MBE) enjoy a higher return over the quarter than firms with similar quarterly earnings forecast errors that fail to meet these expectations. Further, such a premium to MBE, although somewhat smaller, exists in the cases where MBE is likely to have been achieved through earnings or expectations management. The findings also indicate that the premium to MBE is a leading indicator of future performance. This premium and its predictive ability are only marginally affected by whether the MBE is genuine or the result of earnings or expectations management. (C) 2002 Elsevier Science B.V. All rights reserved.
\end{abstract}

JEL classification: G14; M41

Keywords: Earnings expectation; Analysts' forecast; Expectations management; Earnings management; Loss

\footnotetext{
${ }^{2}$ We gratefully acknowledge the helpful comments of Bill Baber, Michael Brennan, Jack Hughes, Patricia Hughes, Jim Ohlson, Joshua Ronen, Jerry Zimmerman, Ross Watts (the editor), Leonard Soffer (the referee) and participants of the accounting workshops at the University of British Columbia, Emory University, Pennsylvania State University, the University of Rochester, Tel-Aviv University, the University of Washington at St. Louis, the 2001 Annual Conference on Financial Economics and Accounting held at the University of Michigan, and the Annual Corporate Earnings Analysis Seminar sponsored by the Center for Investment Research. The capable computer assistance provided by Ashok Natarajan is appreciated. We thank Thomson/First Call (I/B/E/S International, Inc.) for providing the data on analysts' earnings forecasts.

*Corresponding author. Tel.: + 1-310-206-9225; fax: + 1-310-825-3165.

E-mail address: chayn@agsm.ucla.edu (C. Hayn).
} 


\section{Introduction}

Meeting or beating analysts' forecasts of earnings is a notion well entrenched in today's corporate culture. From corporate boards' deliberations to financial press reports and Internet chats, emphasis is placed on whether a company meets its earnings forecasts. The following comment typifies the view of the financial press regarding the importance of meeting Wall Street's expectations:

In January, for the 41st time in 42 quarters since it went public, Microsoft reported earnings that meet or beat Wall Street estimates....This is what chief executives and chief financial officers dream of: quarter after blessed quarter of not disappointing Wall Street. Sure, they dream about other things... But the simplest, most visible, most merciless measure of corporate success in the 1990s has become this one: Did you make your earnings last quarter? (see Fox, 1997, p. 77).

The importance assigned to meeting earnings expectations is not surprising given the valuation relevance of earnings information. Recent anecdotal evidence, however, suggests that companies are not merely passive observers in the game of meeting or beating contemporaneous analysts' expectations (hereafter referred to as $\mathrm{MBE}$ ). Rather, they are active players who try to win the game by altering reported earnings or managing analysts' expectations (see for example McGee, 1997; Vickers, 1999). The motivations often suggested for such a behavior are to maximize the share price, to boost management's credibility for being able to meet the expectations of the company's constituents (e.g., stockholders and creditors), and to avoid litigation costs that could potentially be triggered by unfavorable earnings surprises.

In this paper, we test whether, after controlling for the earnings forecast error for the period, there is a market premium to firms that MBE formed just prior to the release of quarterly earnings. Note that finding a premium to firms that meet or beat market expectations, after controlling for the earnings forecast error for the period, is quite distinct from the well-established finding in the literature of a positive relation between earnings and stock returns first documented by Ball and Brown (1968). For a premium to MBE to exist, the return over the period must be a function of not only unexpected earnings for the period (measured relative to the expectations held at the beginning of the period) but also the manner by which earnings expectations changed over the period, or the expectation path. This point is further discussed in Section 3. Exploring the MBE phenomenon further, we examine the extent to which the data on earnings forecast revisions and earnings surprises are consistent with expectations management or earnings management. Expectations management takes place whenever management purposefully dampens analysts' earnings forecasts to produce a positive earnings surprise (or avoid a negative earnings surprise) upon the earnings release. Earnings management generally involves using accrual accounting in order to produce earnings that surpass the forecasted earnings target. In the cases where earnings or expectations are likely to have been managed, we examine whether the premium to MBE still exists. Finally, various explanations for the potential payoffs from an MBE strategy are explored that are consistent with investor rationality. 
Based on a sample of nearly 130,000 quarterly earnings forecasts made between the years 1983 and 1997 and covering approximately 65,000 firm-quarters, we find that, in line with previous research, instances in which companies meet or beat contemporaneous analysts' estimates have increased considerably in recent years. The trend is common to all quarterly reporting periods and is also present in the annual period. It is observed for both large and small firms. On average, analysts' forecasts made at the beginning of the period overestimate earnings (see similar findings by Barefield and Comiskey, 1975; Brown, 1997; Richardson et al., 1999, among others). However as the end of the reporting period approaches, analysts' optimism (i.e., their overestimation of earnings) turns, as evidenced by the predominance of downward revisions in earnings estimates, into pessimism (i.e., underestimation of earnings). Further, the proportion of negative forecast error cases (measured relative to analysts' earnings forecasts made at the beginning of the quarter) that ends with a zero or positive earnings surprise (measured relative to the most recent analysts' earnings estimate) is greater than the proportion of positive or zero forecast error cases that ends with a negative surprise. These findings are consistent with expectations management taking place late in the reporting period.

Our primary findings show that investors reward firms whose earnings meet or beat analysts' estimates. After controlling for the quarterly forecast error (measured relative to analysts' earnings forecasts made at the beginning of the quarter), the quarter's abnormal returns are positively and significantly associated with the earnings surprise for the quarter (measured as the difference between reported earnings and the most recent earnings estimate at the time of the earnings announcement). The average return over quarters ending with a positive earnings surprise is significantly higher, by about $3.2 \%$, than the return over quarters that have the same overall quarterly earnings forecast error but end with a negative earnings surprise. These results suggest that, independent of the firm's absolute performance, there is a reward to meeting or beating analysts' earnings expectation and a penalty for failing to do so. Ending the period "with a bang" (i.e., with a positive earnings surprise) results in a stock valuation that cannot be explained by the absolute level of the firm's performance.

The results of a premium to MBE are unlikely to be driven by investors' overreaction to good news (see, for example, Zarowin, 1989; DeBondt and Thaler, 1990). Such overreaction, if present, should lead to subsequent market reversals of the abnormal returns generated by the earnings surprise. Yet our tests based on an examination of abnormal returns over both a short window (consisting of the following quarter) and longer windows (up to three years following the earnings announcement) do not detect such a reversal. The premium to earnings surprises appears to be justified on economic grounds: Earnings surprises apparently possess information content with respect to future earnings as evidenced by the positive association between earnings surprises and future firm performance. While the reasons underlying this association are not investigated here, its presence suggests that investors rationally react to earnings surprises. We further find that earnings surprises that are likely to have been obtained through earnings or expectations 
management are associated with only a slightly lower premium and have marginally weaker predictive power with respect to future earnings.

The paper is organized as follows. The next section reviews the recent research on the issue of MBE. Section 3 presents the empirical design, followed by a description of the sample and the data in Section 4. Results are provided in the following sections. The paper concludes with a short summary and suggestions for future research.

\section{Recent studies on MBE}

The phenomenon of meeting or beating expectations has recently attracted interest among researchers. Brown (2001) and Matsumoto (2001) find a disproportional number of cases in recent years where earnings per share are slightly (by a few cents) above analysts' forecasts. They further find an increase over the years in the number of cases where actual earnings per share are exactly on target. Degeorge et al. (1999) ascertain that the MBE strategy is one of three performance thresholds that management tries to meet. Evidence provided by other studies suggests that both earnings manipulation and expectations management are used to accomplish this objective. Burgstahler and Eames (1998) provide evidence that downward revisions of forecasts occur more frequently when the revision would be sufficient to avoid a negative earnings surprise, suggesting managers' influence on analysts' forecast revisions. Such influence is also documented by Skinner (1997), Kasznik and Lev (1995), Francis et al. (1994) and Soffer et al. (2000), who show that companies increasingly tend to warn investors about forthcoming unfavorable earnings. This behavior is consistent with expectations management as a means of MBE. In addition to expectations management, Burgstahler and Eames (1998) find that the time-series behavior of earnings is consistent with companies managing their earnings so as to meet analysts' expectations. Evidence consistent with earnings management to meet earnings forecasts is also provided by Kasznik (1999) and Payne and Robb (1997).

Whether carried out through earnings manipulation, expectations management or both, the benefits from an MBE strategy are not immediately apparent, unless MBE acts as a predictor of the future prospects of the firm. Specifically, for a policy of MBE carried out through earnings management to be successful, investors must be incapable of detecting management's reporting objectives. Likewise, for an MBE policy achieved through expectations management to be successful, investors must be incapable of correcting for an extractable past pattern of earnings forecast revisions and forecast errors.

A net reward to MBE through managing earnings expectations is questionable for yet another reason. Dampening earnings expectations prior to the earnings announcement in order to generate a positive earnings surprise would result in a negative price effect that should offset the positive announcement period return, leaving the total return for the period unchanged. In fact, past research (see Kasznik and Lev, 1995; Soffer et al., 2000) shows a significant decline in the stock price of 
companies who warn investors about forthcoming unfavorable disclosures (thus lowering investors' earnings expectations).

In a related study, Kasznik and McNichols (1999) use a valuation framework to examine whether MBE results in a higher firm valuation and higher forecasted earnings, and the extent to which analysts forecasts of earnings fully incorporate the information contained in MBE. They document a valuation premium to MBE that is associated with future profitability. However, this future profitability is not fully captured by analysts' revisions of future earnings estimates. Lopez and Rees (2000) find that the earnings response coefficient (ERC) is significantly higher for firms that meet analysts' forecasts.

Our analysis contributes to the literature in several respects. First, we provide evidence on the premium to $\mathrm{MBE}$ and relate it to several attributes of the firm and the persistence of MBE incidence. In so doing, we use an information content/event study paradigm rather than a valuation framework, which increases the power of the tests by focusing on the exact arrival time of information to the market. ${ }^{1}$ Second, by analyzing the expectation paths, we are able to make inferences about the manner by which management accomplishes the task of MBE, contributing to the research on management of earnings expectations. In particular, our research method allows us to distinguish between the two managerial tools for achieving MBE: earnings management and expectations management. Third, we examine the relation between the premium to $\mathrm{MBE}$ and the presence of expectations and earnings management. Finally, we examine alternative explanations for the premium to MBE.

\section{Terminology and hypotheses relating to the premium to MBE}

\subsection{Relation between expectation paths and $M B E$}

MBE cases are, by definition, cases with a zero or positive earnings surprise. We examine the premium to $\mathrm{MBE}$ and analyze the extent to which $\mathrm{MBE}$ is achieved through expectations or earnings management. Expectations management takes place whenever management purposefully dampens analysts' earnings forecasts in order to produce a positive earnings surprise (or avoid a negative earnings surprise) upon the earnings release. To relate the MBE phenomenon to expectations management, we examine the "path" of expectation changes over the period. Different "expectation paths" are identified according to the sequence of earnings signals emanating from (1) the direction of analysts' forecast revisions during the period and (2) the sign of the earnings surprise upon earnings announcement. For example, one expectation path consists of a net upward revision in analysts' forecasts during the quarter (as evidenced by earnings forecasts at quarter end that are higher than the forecast initially issued for the quarter) followed by a positive earnings

\footnotetext{
${ }^{1}$ This approach avoids the difficulties associated with estimating basic parameters such as abnormal earnings, terminal value and the cost of capital required by tests based on valuation models (such as Ohlson, 1995).
} 
surprise. Other expectation paths may consist of an upward revision and a negative earnings surprise, a downward revision and no earnings surprise, etc.

\subsection{Terminology}

The expectation path represents the sequence consisting of the direction of the net revision in analysts' forecasts (up, down or zero) and the sign of the earnings surprise (positive, negative or zero). To map out the expectation paths, the first forecast and the last forecast for the quarter must be identified. We define the earliest forecast for quarter $\mathrm{Q}, F_{\text {earliest }}$, as the first forecast for the quarter made subsequent to the announcement of the previous quarter's earnings. ${ }^{2}$ The latest forecast for the quarter, $F_{\text {latest }}$, is the last forecast for the quarter made prior to the release of the earnings announcement for that quarter. The net revision in analysts' forecasts of earnings for the quarter $\left(\mathrm{REV}_{\mathrm{Q}}\right)$ is the difference between the latest earnings forecast and the earliest earnings forecast. The earnings surprise for the quarter $\left(\mathrm{SURP}_{\mathrm{Q}}\right)$ is defined as the difference between the actual earnings number for the quarter $\left(\mathrm{EPS}_{\mathrm{Q}}\right)$ and $F_{\text {latest }}$. The forecast error for the quarter $\left(E R R O R_{\mathrm{Q}}\right)$ is the difference between the actual earnings number and $F_{\text {earliest }}$. Because the set of possible expectation paths differs somewhat for cases with positive, zero or negative forecast errors, we examine the paths separately for each error-sign group as shown in Table 1.

\subsection{Hypotheses relating to expectations management}

If the expectation path is not informative with respect to future firm performance and investors are rational, the course of the expectation path should not affect the abnormal return for the quarter. In particular, there should be no reward to an MBE strategy. Accordingly, the following hypothesis is advanced (expressed in its alternative form):

$\mathrm{H}_{1}$ : After controlling for the forecast error, there is a premium to MBE.

To better understand the nature of the premium (if any), we further test two additional hypotheses. One is that the premium to meeting expectations is similar to that associated with beating expectations. The second is that the premium to MBE and the penalty for failing to meet expectations are, per unit of surprise, of the same magnitude. Stated in their alternative forms, these hypotheses are that, after controlling for the forecast error for the period:

$\mathrm{H}_{2}$ : The premium to meeting expectations is different from the premium to beating expectations.

$\mathrm{H}_{3}$ : The premium to beating expectations is different from the penalty for failing to meet expectations.

\footnotetext{
${ }^{2}$ Earnings forecasts for the current quarter made prior to the release of the previous quarter's report were not considered since their subsequent revision is more likely to be correlated with the content of this report rather than with new information about the current quarter's results.
} 
Table 1

Definitions of expectation paths

\begin{tabular}{|c|c|c|c|}
\hline Forecast error group & $\begin{array}{l}\text { Revision: } \\
F_{\text {latest }}-F_{\text {earliest }}\end{array}$ & $\begin{array}{l}\text { Surprise: EPS }-F_{\text {latest }} \\
(0 \text { or }+ \text { indicates } \\
\text { meeting or beating } \\
\text { expectations) }\end{array}$ & $\begin{array}{l}\text { Expectations path } \\
\text { (a path ending with } \\
\text { "Zero" or "Up" indicates } \\
\text { meeting or beating } \\
\text { expectations) }\end{array}$ \\
\hline \multirow{5}{*}{$\begin{array}{l}\text { Positive forecast errors } \\
\left(\text { EPS }-F_{\text {earliest }}>0\right)\end{array}$} & + & - & Up-Down \\
\hline & + & 0 & Up-Zero \\
\hline & + & + & $\mathrm{Up}-\mathrm{Up}$ \\
\hline & 0 & + & Zero-Up \\
\hline & - & + & Down-Up \\
\hline \multirow{3}{*}{$\begin{array}{l}\text { Zero forecast errors } \\
\left(\text { EPS }-F_{\text {earliest }}=0\right)\end{array}$} & + & - & Up-Down \\
\hline & 0 & 0 & Zero-Zero \\
\hline & - & + & Down-Up \\
\hline \multirow{5}{*}{$\begin{array}{l}\text { Negative forecast errors } \\
\left(\text { EPS }-F_{\text {earliest }}<0\right)\end{array}$} & + & - & Up-Down \\
\hline & 0 & - & Zero-Down \\
\hline & - & - & Down-Down \\
\hline & - & 0 & Down-Zero \\
\hline & - & + & Down-Up \\
\hline
\end{tabular}

${ }^{\mathrm{a}} F_{\text {earliest }}$ is the earliest forecast for the quarter. $F_{\text {latest }}$ is the latest forecast for the quarter.

\subsection{Hypotheses regarding factors influencing the premium to $M B E$}

\subsubsection{Financial position of the firm}

When a firm in financial distress beats its earnings expectation, this conveys information about its ability to survive. That is, in addition to affecting future earnings projections, meeting or beating earnings expectations may alter investors' probability assessment regarding the future survival of the firm. Changes in the likelihood of survival are likely to be more valuable for firms in distress whose a priori probability of survival is considerably less than 1.0. Therefore, we expect a greater premium to MBE for firms in financial distress. Accordingly, we test the hypothesis (stated in its alternative form) that, after controlling for the forecast error for the period:

$\mathrm{H}_{4}$ : The premium to MBE of firms in financial distress is larger than the premium to $\mathrm{MBE}$ of financially sound firms.

\subsection{2. $M B E$ recurrence}

Investors' response to repeated instances of MBE depends on how such outcomes are perceived. If $\mathrm{MBE}$ is regarded as a signal of future performance, repeated instances of $\mathrm{MBE}$ would indicate earnings momentum and produce a greater premium than isolated cases of MBE. If, on the other hand, investors view repeated instances of $\mathrm{MBE}$ as a product of management intervention, the premium associated 
with a persistent pattern of MBE would be lower than that associated with isolated cases of MBE. We thus test the following hypothesis (expressed in the alternative form):

$\mathrm{H}_{5}$ : The premium to MBE of "habitual beaters" of expectations is different from the premium to MBE of "sporadic beaters".

\section{Sample and data}

The sample consists of firm-quarter observations on the Thomas/First Call (I/B/E/S) database of analysts' forecasts that satisfy the following criteria:

(1) There are at least two individual earnings forecasts (not necessarily by the same analyst) for the quarter, which are at least 20 trading days apart.

(2) The release date of the earliest forecast occurs at least three trading days after the release of the previous quarter's earnings.

(3) The release date of the latest forecast precedes the earnings release by at least three days. $^{3}$

The first criterion ensures that there is an initial forecast and a subsequent forecast revision. These are required to be separated in time by at least 20 days so that the second forecast is more likely to represent a true revision rather than a forecast issued almost concurrently with the initial forecast. The average length of time separating the two forecasts in our sample is 55 trading days. The purpose of the second criterion is to prevent "stale" forecasts (i.e., those that are not revised following the previous quarter's earnings announcement) from being included in the analysis. The third criterion is an attempt to ensure that the latest forecast is not "contaminated" by knowledge of the actual earnings number.

The total number of firm-quarters in the sample is 64,872 (containing at least twice as many individual forecasts since our test design requires that both $F_{\text {earliest }}$ and $F_{\text {latest }}$ exist for each firm-quarter), spanning the period from January 1983 to December 1997. The number of firm-quarters increases steadily from an average of about 400 per fiscal quarter in the first five years of the sample period to about 1,500 per fiscal quarter in the last five years of the period. ${ }^{4}$

\footnotetext{
${ }^{3}$ For the second and third criteria, if more than one forecast is released on this day, the average value of the forecasts is used.

${ }^{4}$ The primary analyses were also conducted with two alternative specifications of $F_{\text {earliest }}$ and $F_{\text {latest }}$. Under one alternative specification, we identify $F_{\text {latest }}\left(F_{\text {earliest }}\right)$ as the latest (earliest) forecast made by the same analyst that produced $F_{\text {earliest }}\left(F_{\text {latest }}\right)$. Under the second alternative specification, consensus forecasts (where each consensus reflects at least two individual analysts' forecasts) were used instead of individual forecasts. The results for these alternative specifications, which are not reported for the sake of brevity, were essentially the same as those reported in the paper. This is consistent with Brown and Han (1992) who found similar results using forecasts made by different analysts (comparable with our use of $F_{\text {earliest }}$ and $F_{\text {latest }}$ by different analysts) and forecasts produced by the same analyst.
} 
Actual earnings numbers were retrieved from the $\mathrm{I} / \mathrm{B} / \mathrm{E} / \mathrm{S}$ database. Other financial accounting data were retrieved from Compustat. ${ }^{5}$ Return data were obtained from the Center for Research on Security Prices (CRSP) database.

\section{Evidence on a premium to MBE}

\subsection{Frequency of $M B E$}

To ascertain whether our sample is comparable to those employed by previous research with respect to the time series pattern of $\mathrm{MBE}$, we produced the distribution of earnings surprises over time. Our results (not presented here) show that both MBE have become more prevalent in recent years, as documented by previous research (see, for example, Brown, 1997) as well as contemporaneous studies (see Brown, 2001; Lopez and Rees, 2000; Matsumoto, 2001). Specifically, we find that the proportion of favorable earnings surprises increased from about $50 \%$ in the years 1983-1993 to almost $70 \%$ in the more recent period of 1994-1997. Over these subperiods, the relative frequency of meeting earnings expectations (i.e., a zero surprise) increased from $9 \%$ to $15 \%$ and the relative frequency of beating expectations (a positive surprise) increased from $40 \%$ to $52 \%$.

\subsection{The reward to $M B E$}

To test for the existence of a premium to $\operatorname{MBE}\left(\mathrm{H}_{1}\right)$, we measure the incremental quarterly abnormal return of cases where expectations are met or beaten after controlling for the magnitude of the quarterly forecast error. In testing this hypothesis, we control for the magnitude of the forecast error by placing firm-quarters within each error-sign group into portfolios based on the size of the forecast error calculated as (EPS $-F_{\text {earliest }}$ )/|EPS|. Using 5\% forecast-error intervals results in nine equal-error-size portfolios for each of the positive- and negative-error groups, and one portfolio for the zero-error group.

The portfolio approach used to control for the size of the forecast error has the advantage of not assuming any specific relation (e.g., linear) between CAR and the forecast error. However, it has the drawback of not precluding variation of the forecast errors within the equal-error-size groups, a variation that could be potentially dependent on the path. To alleviate this drawback and to gain additional insights into the MBE phenomenon, we use a regression approach to control for the forecast error. Specifically, we test for an $\mathrm{MBE}$ premium $\left(\mathrm{H}_{1}\right)$ and a differential premium to failing to meet, $\operatorname{MBE}\left(\mathrm{H}_{2}\right.$ and $\left.\mathrm{H}_{3}\right)$ by estimating the following regression:

$$
\begin{aligned}
\mathrm{CAR}_{\mathrm{i}, \mathrm{Q}}= & \beta_{0}+\beta_{1} \mathrm{ERROR}_{\mathrm{i}, \mathrm{Q}}+\beta_{2} \mathrm{SURP}_{\mathrm{i}, \mathrm{Q}}+\beta_{3} \mathrm{DMBE}_{\mathrm{i}, \mathrm{Q}}+\beta_{4} \mathrm{DBEAT}_{\mathrm{i}, \mathrm{Q}} \\
& +\beta_{5} \mathrm{DMBE}_{\mathrm{i}, \mathrm{Q}} * \mathrm{SURP}_{\mathrm{i}, \mathrm{Q}}+\varepsilon_{\mathrm{i}, \mathrm{Q}},
\end{aligned}
$$

\footnotetext{
${ }^{5}$ In those instances where the I/B/E/S earnings number differed substantially (by more than $50 \%$ ) from the earnings number reported by Compustat and the difference could not be explained by a special item (since I/B/E/S reports an "adjusted" earnings number), we eliminated the observation. See Abarbanell and Lehavy (2000) for a discussion of the difficulties in comparing EPS figures across databases.
} 
where $\mathrm{i}$ is the firm index and $\mathrm{Q}$ designates the quarter. CAR is the beta-adjusted cumulative abnormal return over the period beginning two days following the date of $F_{\text {earliest }}$ and ending one day after the release of the quarter's results. ${ }^{6}$ The overall forecast error for the quarter, ERROR, and the end-of-quarter earnings surprise, SURP, are measured as described above and deflated by the firm's stock price at the beginning of the quarter. DMBE and DBEAT are dummy variables that receive the value of 1.0 if, respectively, SURP $\geqslant 0$ (earnings met or exceeded expectations) and SURP $>0$ (earnings exceeded expectations). Otherwise, these variables receive the value of zero. The interactive variable, DMBE*SURP, captures the extent to which the reward to beating expectations differs from the penalty for failing to meet expectations. ${ }^{7}$

We expect $\beta_{1}$ to be positive and significant, in line with the findings of the vast body of research on the information content of earnings. Under the null of $\mathrm{H}_{1}$, the coefficients $\beta_{2}$ and $\beta_{3}$ are not expected to be significantly different from zero. Under $\mathrm{H}_{2}, \beta_{4}$ should not be significantly different from zero if the premium to beating expectations is similar to that for meeting them. Under the null of $\mathrm{H}_{3}, \beta_{5}$ should not be different from zero if the reward to MBE is comparable with the penalty for failing to meet expectations.

Table 2 reports the results of testing $\mathrm{H}_{1}$ (premium to $\mathrm{MBE}$ ) and $\mathrm{H}_{2}$ (differential premium to beating versus merely meeting expectations) for the portfolio tests. The table presents the period abnormal returns by expectation path, controlling for the period's forecast error. As noted earlier, this control is obtained through the construction of equal-error-size portfolios, in $5 \%$ increments. The table shows that within almost every error-size portfolio, the period abnormal return, $\mathrm{CAR}_{\mathrm{Q}}$, associated with beating expectations, that is, paths ending with a positive earnings surprise ( $\bullet$-Up paths), is significantly higher than that associated with paths ending with an unfavorable earnings surprise (•-Down paths). ${ }^{8}$ For example, positive error cases within the $0-5 \%$ error-size group that end with a positive earnings surprise have an average CAR of $2.9 \%$ while those in this same group that end with a negative earnings surprise show an average CAR of $1.5 \%$. The comparable numbers for the $30-35 \%$ error-size group are an average CAR of about $8.5 \%$ versus an average CAR of $5.2 \%{ }^{9}$

\footnotetext{
${ }^{6}$ Alternative measures of abnormal returns for a period were computed: the cumulative beta-adjusted abnormal return (which assumes daily rebalancing) over the period, the period's "buy-and-hold" betaadjusted abnormal return, the period's cumulative size-adjusted returns, and an average "per-day" measure of abnormal returns (to account for return intervals of different lengths). Use of these measures led to essentially the same results.

${ }^{7}$ Note that this variable takes on a value of zero when expectations are met.

${ }^{8}$ The average $\mathrm{CAR}_{\mathrm{Q}}$ for the $\bullet$-Down paths and that of the $\bullet$-Up paths is significantly different (at the 0.01 level or higher) for 13 of the 18 portfolios in Panel A.

${ }^{9}$ Note that for the positive error cases, abnormal returns for the Up-Up path tend to be somewhat higher than for the two other MBE paths (Down-Up and Zero-Up). Similarly, for the negative error cases, abnormal returns for the Down-Down path tend to be lower than for the two other paths where expectations were not met (Up-Down and Zero-Down). Because our main concern is the distinction between the abnormal returns to MBE paths versus other paths, we offer no formal hypotheses regarding those differences.
} 
Table 2

Mean quarterly abnormal returns $\left(\mathrm{CAR}_{\mathrm{Q}}\right)$ by sign and size of forecast error, and expectation path

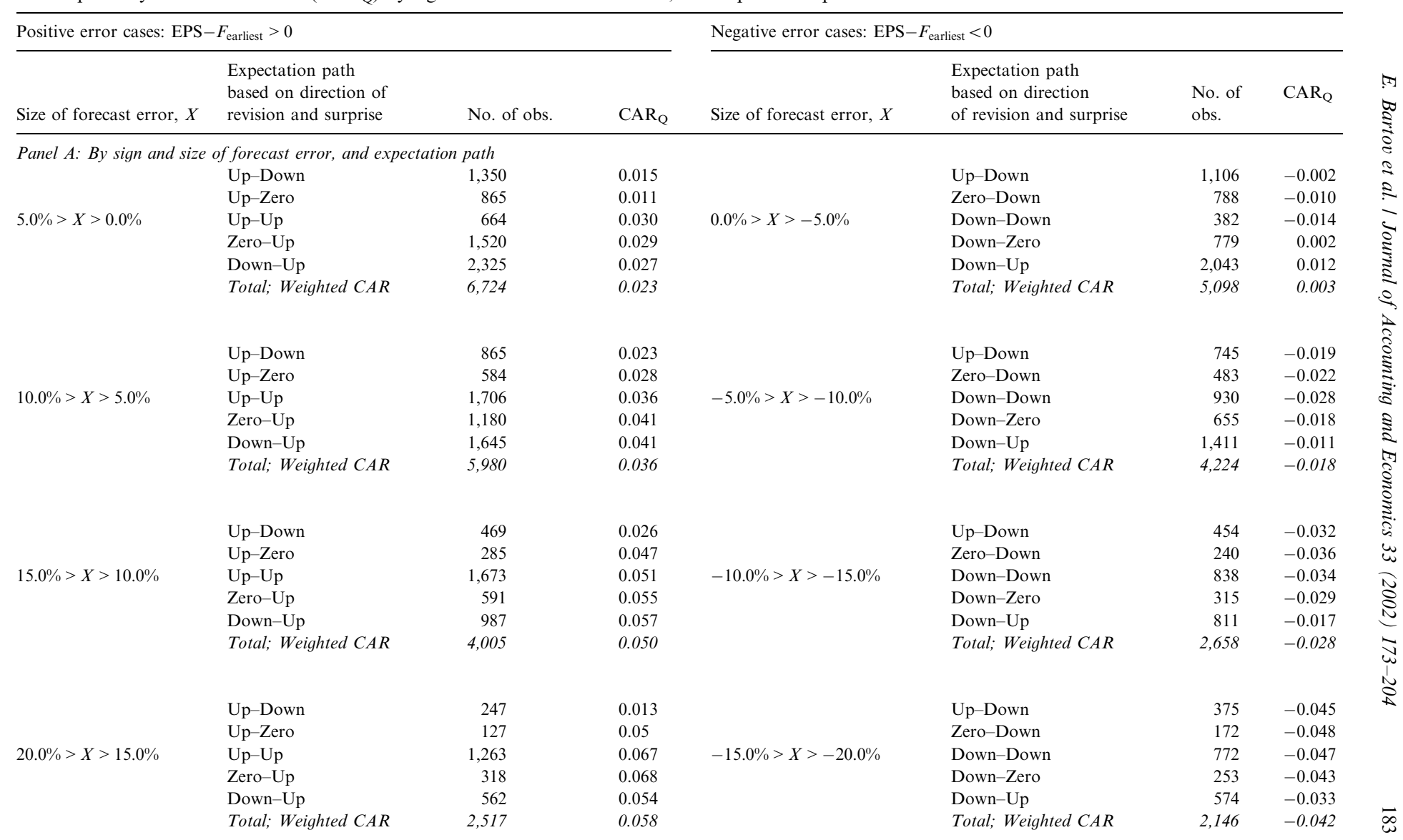




\begin{tabular}{|c|c|c|c|c|c|c|c|}
\hline \multicolumn{4}{|c|}{ Positive error cases: EPS $-F_{\text {earliest }}>0$} & \multicolumn{4}{|c|}{ Negative error cases: EPS $-F_{\text {earliest }}<0$} \\
\hline Size of forecast error, $X$ & $\begin{array}{l}\text { Expectation path } \\
\text { based on direction of } \\
\text { revision and surprise }\end{array}$ & No. of obs. & $\mathrm{CAR}_{\mathrm{Q}}$ & Size of forecast error, $X$ & $\begin{array}{l}\text { Expectation path } \\
\text { based on direction } \\
\text { of revision and surprise }\end{array}$ & $\begin{array}{l}\text { No. of } \\
\text { obs. }\end{array}$ & $\mathrm{CAR}_{\mathrm{Q}}$ \\
\hline \multirow{6}{*}{$25.0 \%>X>20.0 \%$} & Up-Down & 180 & 0.033 & \multirow{6}{*}{$-20.0 \%>X>-25.0 \%$} & Up-Down & 284 & -0.053 \\
\hline & Up-Zero & 75 & 0.049 & & Zero-Down & 132 & -0.062 \\
\hline & Up-Up & 982 & 0.077 & & Down-Down & 663 & -0.060 \\
\hline & Zero-Up & 815 & 0.071 & & Down-Zero & 154 & -0.055 \\
\hline & Down-Up & 396 & 0.074 & & Down-Up & 397 & -0.048 \\
\hline & Total; Weighted CAR & 2,448 & 0.070 & & Total; Weighted CAR & 1,630 & -0.056 \\
\hline \multirow{6}{*}{$30.0 \%>X>25.0 \%$} & Up-Down & 168 & 0.038 & \multirow{6}{*}{$-25.0 \%>X>-30.0 \%$} & Up-Down & 185 & -0.059 \\
\hline & Up-Zero & 62 & 0.051 & & Zero-Down & 56 & -0.064 \\
\hline & Up-Up & 794 & 0.092 & & Down-Down & 515 & -0.069 \\
\hline & Zero-Up & 151 & 0.09 & & Down-Zero & 78 & -0.056 \\
\hline & Down-Up & 304 & 0.057 & & Down-Up & 251 & -0.056 \\
\hline & Total; Weighted CAR & 1,479 & 0.077 & & Total; Weighted CAR & 1,085 & -0.063 \\
\hline \multirow{6}{*}{$35.0 \%>X>30.0 \%$} & Up-Down & 101 & 0.054 & \multirow{6}{*}{$-30.0 \%>X>-35.0 \%$} & Up-Down & 151 & -0.066 \\
\hline & Up-Zero & 57 & 0.072 & & Zero-Down & 75 & -0.064 \\
\hline & $\mathrm{Up}-\mathrm{Up}$ & 542 & 0.09 & & Down-Down & 465 & -0.076 \\
\hline & Zero-Up & 88 & 0.091 & & Down-Zero & 106 & -0.061 \\
\hline & Down-Up & 221 & 0.068 & & Down-Up & 236 & -0.057 \\
\hline & Total; Weighted CAR & 1,009 & 0.081 & & Total; Weighted CAR & 1,033 & -0.068 \\
\hline \multirow{6}{*}{$40.0 \%>X>35.0 \%$} & Up-Down & 65 & 0.059 & \multirow{6}{*}{$-35.0 \%>X>-40.0 \%$} & Up-Down & 134 & -0.070 \\
\hline & Up-Zero & 22 & 0.079 & & Zero-Down & 44 & -0.077 \\
\hline & $\mathrm{Up}-\mathrm{Up}$ & 407 & 0.094 & & Down-Down & 426 & -0.089 \\
\hline & Zero-Up & 63 & 0.089 & & Down-Zero & 81 & -0.073 \\
\hline & Down-Up & 135 & 0.068 & & Down-Up & 178 & -0.062 \\
\hline & Total; Weighted CAR & 692 & 0.085 & & Total; Weighted CAR & 863 & -0.078 \\
\hline \multirow{6}{*}{$X>40.0 \%$} & Up-Down & 406 & 0.067 & \multirow{6}{*}{$X<-40.0 \%$} & Up-Down & 1,868 & -0.086 \\
\hline & Up-Zero & 145 & 0.097 & & Zero-Down & 692 & -0.083 \\
\hline & $\mathrm{Up}-\mathrm{Up}$ & 2,102 & 0.108 & & Down-Down & 7,614 & -0.099 \\
\hline & Zero-Up & 321 & 0.093 & & Down-Zero & 714 & -0.095 \\
\hline & Down-Up & 752 & 0.083 & & Down-Up & 1,941 & -0.076 \\
\hline & Total; Weighted CAR & 3,726 & 0.097 & & Total; Weighted CAR & 12,829 & -0.093 \\
\hline
\end{tabular}




\begin{tabular}{|c|c|c|c|c|c|c|}
\hline \multirow[b]{2}{*}{$\begin{array}{l}\text { Sign of } \\
\text { forecast } \\
\text { error }\end{array}$} & \multirow[b]{2}{*}{$\begin{array}{l}\text { No. of } \\
\text { obs. }\end{array}$} & \multirow[b]{2}{*}{$\begin{array}{l}\text { Expectation path } \\
\text { based on direction } \\
\text { of revision and } \\
\text { surprise }^{\mathrm{a}}\end{array}$} & \multirow[b]{2}{*}{$\begin{array}{l}\text { Expectations } \\
\text { were: }\end{array}$} & \multirow[b]{2}{*}{$\begin{array}{l}\text { Mean } \text { CAR }_{Q} \\
\text { across } \\
\text { portfolios }^{b}\end{array}$} & \multicolumn{2}{|c|}{ Difference between $\mathrm{CAR}_{\mathrm{Q}}$ for } \\
\hline & & & & & $\begin{array}{l}\text {--Zero and } \\
\text {--Down paths } \\
\text { (meeting vs. failing to } \\
\text { meet expectations) } \\
\text { ( } t \text {-statistic) }\end{array}$ & $\begin{array}{l}\bullet-\mathrm{Up} \text { and } \bullet \text {-Down } \\
\text { paths } \\
\text { (beating vs. failing to } \\
\text { meet expectations) } \\
\text { ( } t \text {-statistic) }\end{array}$ \\
\hline \multicolumn{7}{|c|}{ Panel B: Summary by sign of forecast error and expectation path } \\
\hline Positive error cases & 3,851 & Up-Down & Not met & 0.027 & & \\
\hline EPS $-F_{\text {earliest }}>0$ & $\begin{array}{r}2,222 \\
22,507\end{array}$ & $\begin{array}{l}\text { Up-Zero } \\
\bullet-\mathrm{Up}^{\mathrm{c}}\end{array}$ & $\begin{array}{l}\text { Met } \\
\text { Beat }\end{array}$ & $\begin{array}{l}0.033 \\
0.059\end{array}$ & $\begin{array}{r}0.006 \\
(1.71)\end{array}$ & $\begin{array}{r}0.032 \\
(12.17)\end{array}$ \\
\hline Zero error cases & 1,186 & Up-Down & Not met & -0.008 & & \\
\hline EPS $-\mathrm{F}_{\text {earliest }}=0$ & $\begin{array}{l}1,557 \\
1,983\end{array}$ & $\begin{array}{l}\text { Zero-Zero } \\
\text { Down-Up }\end{array}$ & $\begin{array}{l}\text { Met } \\
\text { Beat }\end{array}$ & $\begin{array}{l}0.008 \\
0.010\end{array}$ & $\begin{array}{r}0.016 \\
(2.67)\end{array}$ & $\begin{array}{r}0.018 \\
(3.40)\end{array}$ \\
\hline Negative error cases & 20,589 & --Down ${ }^{\mathrm{c}}$ & Not met & -0.066 & & \\
\hline EPS $-F_{\text {earliest }}<0$ & $\begin{array}{l}3,135 \\
7,842\end{array}$ & $\begin{array}{l}\text { Down-Zero } \\
\text { Down-Up }\end{array}$ & $\begin{array}{l}\text { Met } \\
\text { Beat }\end{array}$ & $\begin{array}{l}-0.040 \\
-0.029\end{array}$ & $\begin{array}{r}0.026 \\
(8.21)\end{array}$ & $\begin{array}{r}0.037 \\
(15.22)\end{array}$ \\
\hline
\end{tabular}

${ }^{\mathrm{a}}$ Expectation paths are defined by the sign of the forecast revision and the earnings surprise. The forecast revision is the difference between the latest forecast and the earliest forecast for the quarter, $F_{\text {latest }}-F_{\text {earliest. }}$. The earnings surprise is the difference between the actual earnings and the latest forecast for the quarter, EPS $-F_{\text {latest. }}$. The forecast error is the difference between the actual earnings and the earliest forecast for the quarter, EPS $-F_{\text {earliest }}$.

${ }^{\mathrm{b}} \mathrm{CAR}_{\mathrm{Q}}$ is the cumulative abnormal return over the quarter beginning two days after $F_{\text {earliest }}$ and ending the day following the earnings release.

${ }^{\mathrm{C}} \bullet$-Up refers to the three paths ending with a positive surprise. Similarly, $\bullet$-Down refers to the three paths ending with a negative surprise.

The sample consists of all cases with available forecast and return data over the 1983-1997 period that meet the sample selection criteria. 
Panel B of Table 2 summarizes the results in Panel A across paths. Each value in this panel is the average of the $\mathrm{CAR}_{\mathrm{Q}}$ pertaining to the expectation path. ${ }^{10}$ As the results for the positive error cases show (see first row of Panel B), after controlling for the magnitude of the forecast error for the quarter, the $\bullet-U p$ paths (i.e., the cases of beating expectations) are associated with the highest $\mathrm{CAR}_{\mathrm{Q}}$ of all paths, having an average $\mathrm{CAR}_{\mathrm{Q}}$ of $5.9 \%$ as compared with $3.3 \%$ for the Up-Zero path (i.e., the cases of meeting expectations) and $2.7 \%$ for the Up-Down path (i.e., the cases of failing to meet expectations). Similar results are obtained for cases with a negative forecast error, with the Down-Up path having an average $\mathrm{CAR}_{\mathrm{Q}}$ of $-2.9 \%$ while the --Down paths and the Down-Zero path have considerably lower $\mathrm{CAR}_{\mathrm{Q}}$, of $-6.6 \%$ and $-4.0 \%$, respectively. Likewise, within the zero-error portfolio, the $\mathrm{CAR}_{\mathrm{Q}}$ for the expectation path that ends with a positive earnings surprise (Zero-Up) is larger by $1.8 \%(1.0 \%$ versus $-0.8 \%)$ than that ending with a negative earnings surprise. Across all error groups, the average $\mathrm{CAR}_{\mathrm{Q}}$ for paths ending with a favorable surprise (beating expectations) is greater by about $3.2 \%$ than those ending with an unfavorable surprise. The above differences in $\mathrm{CAR}_{\mathrm{Q}}$ are significant at the $1 \%$ significance level or higher, using the paired-difference $t$-test.

As explained in the introduction, the finding of a premium to the earnings surprise is unrelated to the well-established association between unexpected earnings and returns. This earnings-return association manifests itself in our sample by the larger CAR for cases with a larger earnings forecast error. For example, the weighted average CAR for observations with positive forecast errors that are in the $0-5 \%$ error group is $2.3 \%$ (see the upper left block in Panel A of Table 2). In contrast, the weighted CAR for the observations with positive forecast errors of 30-35\% error group is much larger, averaging $8.1 \%$ (see the bottom left block in Panel A of Table 2).

Similarly, the weighted average CAR for the negative-error observations in the $0 \%$ to $-5 \%$ error group is $0.03 \%$ whereas observations in the $-30 \%$ to $-35 \%$ portfolio experienced a weighted average CAR of $-6.8 \%$. The presence of an earnings-return association, however, does not imply any significant difference in CAR between cases that end with a positive or negative earnings surprise within each of these equal-error-size groups.

Similar findings regarding the reward to MBE are reached when $\mathrm{H}_{1}$ and $\mathrm{H}_{2}$ are tested using regression (1). As shown in Table 3 , the coefficient $\beta_{2}$, estimated from the full sample, is positive and significant, suggesting that the earnings surprise affects the return for the quarter, even after controlling for ERROR, the overall quarterly forecast error (which is, as expected, a significant variable). ${ }^{11}$ The regression results also suggest that beating expectations is associated with a higher

\footnotetext{
${ }^{10}$ For the zero-error cases there is only one error-size portfolio $\left(\right.$ EPS $\left.-F_{\text {earliest }}=0\right)$.

${ }^{11}$ The firm-quarter observations are not strictly independent because of the presence of multi-quarter observations for each firm. To determine whether the inferences are sensitive to this dependence, the regressions presented in Table 3 were also estimated from a subsample in which a single quarter was randomly drawn from each of the approximately 5,800 distinct firms in the sample. The results and, in particular, the significance of the variables of interest, are similar to those obtained for the full sample.
} 
Table 3

Results of regression (1):

$$
\mathrm{CAR}_{\mathrm{i}, \mathrm{Q}}=\beta_{0}+\beta_{1} \mathrm{ERROR}_{\mathrm{i}, \mathrm{Q}}+\beta_{2} \mathrm{SURP}_{\mathrm{i}, \mathrm{Q}}+\beta_{3} \mathrm{DMBE}_{\mathrm{i}, \mathrm{Q}}+\beta_{4} \mathrm{DBEAT}_{\mathrm{i}, \mathrm{Q}}+\beta_{5} \mathrm{DMBE}_{\mathrm{i}, \mathrm{Q}} * \mathrm{SURP}_{\mathrm{i}, \mathrm{Q}}+\varepsilon_{\mathrm{I}, \mathrm{Q}}
$$

by subperiod and quarter ${ }^{\mathrm{a}}$

( $t$-statistics are provided in parentheses)

\begin{tabular}{|c|c|c|c|c|c|c|c|c|}
\hline Full sample & No. of Obs. & $\beta_{0}$ & $\beta_{1}$ & $\beta_{2}$ & $\beta_{3}$ & $\beta_{4}$ & $\beta_{5}$ & $R^{2}(\%)$ \\
\hline & 64,872 & -0.028 & 0.407 & 0.534 & 0.023 & 0.034 & 0.434 & \\
\hline & & $(-27.63)$ & $(47.82)$ & $(8.15)$ & $(11.76)$ & (16.49) & (3.02) & 8.76 \\
\hline \multirow[t]{2}{*}{ Subperiod 1: 1983-1993 } & 36,976 & -0.026 & 0.468 & 0.463 & 0.023 & 0.029 & 0.224 & 8.12 \\
\hline & & $(-21.67)$ & $(42.79)$ & $(7.56)$ & $(7.84)$ & $(8.42)$ & $(1.78)$ & \\
\hline \multirow[t]{2}{*}{ Subperiod 2: 1994-1997 } & 27,896 & -0.034 & 0.394 & 0.597 & 0.035 & 0.039 & 0.842 & 9.94 \\
\hline & & $(-17.42)$ & $(32.46)$ & $(6.32)$ & $(8.79)$ & (13.12) & $(3.46)$ & \\
\hline \multicolumn{9}{|l|}{ By quarter ${ }^{\mathrm{b}}$} \\
\hline \multirow[t]{2}{*}{ Quarter 1} & 14,721 & -0.035 & 0.586 & 0.364 & 0.022 & 0.024 & 0.687 & 8.32 \\
\hline & & $(-15.56)$ & $(25.42)$ & $(3.25)$ & $(4.97)$ & $(3.92)$ & (2.97) & \\
\hline \multirow[t]{2}{*}{ Quarter 2} & 15,276 & -0.026 & 0.612 & 0.374 & 0.020 & 0.037 & 0.496 & 9.41 \\
\hline & & $(-12.12)$ & (30.45) & $(2.96)$ & (4.67) & (6.74) & (1.47) & \\
\hline \multirow[t]{2}{*}{ Quarter 3} & 16,306 & -0.029 & 0.489 & 0.580 & 0.028 & 0.044 & 0.554 & 7.88 \\
\hline & & $(-13.11)$ & $(25.72)$ & $(6.79)$ & (5.61) & (8.43) & (1.96) & \\
\hline \multirow[t]{2}{*}{ Quarter 4} & 18,134 & -0.027 & 0.316 & 0.492 & 0.030 & 0.031 & 0.834 & 6.92 \\
\hline & & $(-6.04)$ & (16.42) & (5.12) & (6.243) & $(5.56)$ & (2.88) & \\
\hline
\end{tabular}

${ }^{a}$ The most extreme $1 \%$ of the cases at either end of the distribution each year for ERROR and SURP were truncated.

${ }^{\mathrm{b}}$ Only calendar-year firms were considered in this analysis.

$\mathrm{CAR}_{\mathrm{Q}}$ is the cumulative abnormal return over the quarter beginning two days after the earliest forecast and ending the day following the earnings release. ERROR is the forecast error computed as the difference between the actual earnings and the earliest forecast for the quarter, EPS- $F_{\text {earliest }}$, standardized by price at the beginning of the quarter.

SURP is the earnings surprise computed as the difference between the actual earnings and the latest forecast for the quarter, EPS- $F_{\text {latest }}$, standardized by price at the beginning of the quarter.

DMBE is a dummy variable that takes on the value of 1 if $S U R P \geqslant 0$ and 0 otherwise.

DBEAT is a dummy variable that takes on the value of 1 if SURP $>0$ and 0 otherwise.

The sample consists of all cases with forecast and return data over the 1983-1997 period that meet the sample selection criteria. 
return than just meeting expectations as borne out by the positive and significant coefficients on DBEAT $\left(\beta_{4}\right)$.

The coefficient $\beta_{3}$ of 0.023 (see first line of Table 3) suggests that the quarterly return for firms that meet or beat their earnings expectations ("MBE firms") is $2.3 \%$ above that of all other firms, independent of the magnitude of the positive earnings surprise. In addition to this constant premium, the abnormal return to MBE firms is affected by the magnitude of the earnings surprise. The estimate of $\beta_{2}$, the coefficient of SURP is 0.534 , suggesting that a $1 \%$ earnings surprise is associated with an incremental quarterly return of about $0.5 \%$. These incremental returns indicated by the magnitudes of $\beta_{2}$ and $\beta_{3}$ are economically important given that the average quarterly return of our sample firms during the examined period is about $3.0 \%$. To illustrate, the quarterly return of firms with a price-to-earnings ratio of 10 that exceed their earnings expectations prevailing just before the quarterly earnings announcements by, say, 5\%, enjoy an average quarterly return of about $5.3 \%$ $(3.0 \%+(2.3 \%+(5 \% / 10 \times 0.534)))$, or a return that is 1.8 times that of all other firms. These values are consistent with the return differentials between MBE and non-MBE paths obtained from the portfolio tests and summarized in panel B of Table 2. The results further show that the reward to beating expectations is higher than the penalty for failing to meet them $\left(\mathrm{H}_{3}\right)$, as indicated by the positive and significant sign of $\beta_{5}$.

While not formally hypothesized, we also examine whether a significant premium to MBE has persisted throughout the examined period by dividing the overall period into two subperiods: 1983-1993 and 1994-1997. The motivation for this examination stems from both the finding of a greater frequency of MBE in recent years as well as the greater dissemination of analysts' estimates. The subperiods were selected to reflect the increased use of analysts' estimates as a benchmark for firm performance and the prevalence of the "expectations game", which appear to have emerged in the mid-1990s. ${ }^{12}$

As shown in Table 3, while the premium to MBE has indeed been present throughout the 15-year period of the sample, its magnitude appears to be somewhat greater in recent years. Table 3 also shows that the premium to MBE is not confined to any fiscal quarter. The coefficients of SURP and DMBE $\left(\beta_{2}\right.$ and $\left.\beta_{3}\right)$ are positive and significant for each of the quarters, and not significantly different across quarters.

\footnotetext{
${ }^{12}$ Several sources began providing earnings benchmarks based on analysts' forecasts on the Internet in the mid-1990s. Perhaps the best known, First Call, introduced its service to the web in 1994. Other services quickly followed in late 1994 and 1995 with online reports including Hoover's Online, the Street Advisor and CNNfn. Also, during this period, earnings announcements in the press began to contain information as to whether the reported earnings met or beat expectations. (A search of the key words "met expectations" or "beat expectations" in earnings announcements reveals a sharp increase in the frequency of these terms from 1994 to 1995 onward.) Further, as noted earlier, Brown (2001) and Matsumoto (2001), as well as our unreported results, show that the average analyst forecast error has become positive in recent years.
} 


\subsection{The information content of forecast revisions relative to earnings announcements}

The finding that the market rewards certain expectation paths is consistent with the notion that investors assign less weight to analysts' forecast revisions made during the quarter than to earnings surprises occurring when earnings are announced. This notion is supported by the relative magnitudes of the coefficients for ERROR and SURP in regression (1) (see Table 3). The coefficient for ERROR $\left(\beta_{1}\right)$ in that regression estimated from the full sample is 0.407 and the coefficient for SURP $\left(\beta_{2}\right)$ is 0.534 . Since, by definition, ERROR $=\mathrm{SURP}+\mathrm{REV}$, decomposing ERROR in the regression would yield a coefficient for the revision variable equal to $\beta_{1}$, or 0.407 . This value is less than half the magnitude of the coefficient for SURP in the "decomposed" regression, which is equal to $\beta_{1}+\beta_{2}$, or 0.941 . This result suggests that while revisions in analysts' forecasts are a significant factor in explaining the period return, the effect of the surprise is much greater than that of the revision.

To further explore this finding of a lower weight assigned by investors to forecast revisions as compared with earnings surprises, we contrast the stock price reaction to the release of forecast revisions with the response to earnings releases of a similar magnitude. The results (not shown) reveal that after controlling for the magnitude of the revision and the surprise, the stock price response to earnings announcements is, on average, 1.5 times stronger than the response to analysts' forecast revisions. These results are reinforced by another analysis we conducted which indicates that analysts' revisions during the quarter are less likely to trigger a revision in next year's earnings forecasts than are earnings surprises occurring when the earnings report is released.

The lower weight assigned by investors to revisions in earnings forecasts relative to earnings surprises could rationalize expectations management since the penalty for dampening expectations with its resulting downward earnings forecast revision is outweighed by the premium associated with the subsequent favorable earnings surprises.

\subsection{The reward to $M B E$ as a function of the firm's financial position and $M B E$ recurrence}

Hypotheses $\mathrm{H}_{4}$, and $\mathrm{H}_{5}$ predict differential premiums to MBE for, respectively, firms in financial distress versus financially sound firms and firms that consistently beat expectations ("habitual beaters") versus those that only occasionally do so ("sporadic beaters"). These are tested by augmenting regression (1) with a variable, DMBE ${ }^{\text {subset} * S U R P, ~ w h i c h ~ c a p t u r e s ~ t h e ~ h y p o t h e s i z e d ~ e f f e c t s ~ r e g a r d i n g ~ t h e ~}$ firm's financial position and $\mathrm{MBE}$ persistence (quarter and firm notations are omitted):

$$
\begin{aligned}
\mathrm{CAR}= & \delta_{0}+\delta_{1} \mathrm{ERROR}+\delta_{2} \mathrm{SURP}+\delta_{3} \mathrm{DMBE}+\delta_{4} \mathrm{DMBE} \\
& +\delta_{5} \mathrm{DMBE} * \mathrm{SURP}+\delta_{6} \mathrm{DMBE}^{\text {subset }} * \mathrm{SURP}+\varepsilon .
\end{aligned}
$$


This additional variable receives the value of 1.0 if $\mathrm{SURP} \geqslant 0$ (i.e., $\mathrm{DMBE}=1$ ) and the case belongs to the subset of observations (financially distressed firms $\left(\mathrm{H}_{4}\right)$ or "habitual beaters" $\left(\mathrm{H}_{5}\right)$ ) to which the specific hypothesis refers. ${ }^{13}$

To test $\mathrm{H}_{4}$, firms in financial distress are defined in two ways: those with Altman's $Z$-scores below 2.0 (see Altman, 1983) or those with S\&P bond ratings below "investment grade". In testing $\mathrm{H}_{5}$, "habitual beaters" are defined for each quarter as those firms that met or exceeded earnings expectations in at least nine of the most recent twelve quarters.

The results of testing $\mathrm{H}_{4}$ are presented in row 1 of Table 4 . They indicate that the market rewards financially distressed firms that manage to meet or beat expectations with an additional premium, as evidenced by the positive and significant coefficients $\delta_{4}$ and $\delta_{6}$. As the second row of Table 4 shows, "habitual beaters" fare better than firms that occasionally $\mathrm{MBE}$, as evidenced by the fact that both $\delta_{4}$ and $\delta_{6}$ are positive and significant for this subset. Rather than discounting the favorable earnings surprises of firms that repeatedly produce such surprises, investors appear to value them even more. This finding is in line with the findings of Kasznik and McNichols (1999) that the premium is more pronounced for "habitual beaters" as well as the "momentum" story and the related findings by Barth et al. (1999).

\section{Expectations management and $\mathrm{MBE}$}

\subsection{Hypotheses}

Existence of a premium to MBE suggests that managers have an incentive to manage earnings or expectations in order to MBE. ${ }^{14}$ To test for the presence of expectations management, we perform two tests. First, we contrast the actual earnings surprise distribution with the hypothetical distribution assuming no interim revision in analysts' earnings forecasts. Note that if there were no interim revisions, the surprise distribution would be identical to that of the forecast error since, $F_{\text {latest }}$ would be equal to $F_{\text {earliest }}$. If expectations management occurs such that expectations are dampened leading to downward revisions in earnings estimates, we would expect to find that negative earnings surprises are less frequent than negative forecast errors. Conversely, if interim forecast revisions only represent the arrival of new information without any managerial effort to manage expectations, there should be no difference between the frequency of negative earnings surprises and negative forecast errors. Accordingly, the following hypothesis is tested (in alternative form):

$\mathrm{H}_{6}$ : The relative frequency of negative earnings surprises is smaller than the relative frequency of negative forecast errors.

\footnotetext{
${ }^{13}$ To illustrate, in testing $\mathrm{H}_{4}$, DMBE ${ }^{\text {subset }}$ is set equal to 1.0 for all MBE cases of a firm defined to be in financial distress.

${ }^{14}$ Matsumoto (2001) examines firm characteristics that might be associated with the incentive to achieve MBE. She finds that firms with higher institutional ownership, higher litigation risk and higher growth prospects are more likely to guide analysts' forecasts downward to ensure that earnings will meet expectations.
} 
Table 4

Results of regression (2):

$$
\mathrm{CAR}_{\mathrm{i}, \mathrm{Q}}=\delta_{0}+\delta_{1} \mathrm{ERROR}+\delta_{2} \mathrm{SURP}+\delta_{3} \mathrm{DMBE}+\delta_{4} \mathrm{DMBE}^{\text {subset }}+\delta_{5} \mathrm{DMBE} * \mathrm{SURP}+\delta_{6} \mathrm{DMBE} \text { subset } * \mathrm{SURP}+\varepsilon_{\mathrm{i}, \mathrm{Q}}
$$

by financial position and persistence of $\mathrm{MBE}^{\mathrm{a}}$

$(t$-statistics are provided in parentheses)

\begin{tabular}{|c|c|c|c|c|c|c|c|c|}
\hline Tested hypothesis (in alternative form) & $\delta_{0}$ & $\delta_{1}$ & $\delta_{2}$ & $\delta_{3}$ & $\delta_{4}$ & $\delta_{5}$ & $\delta_{6}$ & $R^{2}(\%)$ \\
\hline $\begin{array}{l}\mathrm{H}_{4} \text { : The premium to MBE of firms in financial distress is } \\
\text { larger than the premium to MBE of financially sound firms }{ }^{\mathrm{b}} \\
\text { (DMBE }{ }^{\text {subset }}=1 \text { for } 4,622 \text { financially distressed firms; total sample } \\
\text { consists of } 42,655 \text { firms with sufficient data to compute } \\
\text { Altman Z-score) }\end{array}$ & $\begin{array}{r}-0.032 \\
(-19.46)\end{array}$ & $\begin{array}{r}0.381 \\
(17.57)\end{array}$ & $\begin{array}{r}0.445 \\
(4.63)\end{array}$ & $\begin{array}{c}0.037 \\
(7.89)\end{array}$ & $\begin{array}{c}0.018 \\
(3.64)\end{array}$ & $\begin{array}{c}0.514 \\
(2.67)\end{array}$ & $\begin{array}{c}0.126 \\
(2.42)\end{array}$ & 6.81 \\
\hline $\begin{array}{l}\mathrm{H}_{5} \text { : The premium to MBE of "habitual beaters" is different } \\
\text { from the premium to MBE of "sporadic beaters"" } \\
\text { (DMBE }{ }^{\text {subset }}=1 \text { for } 5,332 \text { habitual beaters; total sample } \\
\text { consists of } 23,862 \text { firms with at least } 12 \text { preceding } \\
\text { quarters of forecast data) }\end{array}$ & $\begin{array}{r}-0.030 \\
(-18.74)\end{array}$ & $\begin{array}{c}0.424 \\
(20.62)\end{array}$ & $\begin{array}{c}0.536 \\
(6.76)\end{array}$ & $\begin{array}{c}0.029 \\
(8.82)\end{array}$ & $\begin{array}{r}0.050 \\
(4.12)\end{array}$ & $\begin{array}{c}0.480 \\
(3.97)\end{array}$ & $\begin{array}{c}0.742 \\
(3.54)\end{array}$ & 8.21 \\
\hline
\end{tabular}

${ }^{\mathrm{a}}$ The most extreme $1 \%$ of the cases at either end of the distribution each year for ERROR and SURP were truncated.

${ }^{\mathrm{b}}$ In this analysis, financially distressed firms are those with an Altman $Z$-score below 2.0 (see Altman, 1983); firms with a $Z$-score above 3.0 are defined as financially sound. (Firms with a $Z$-score between 2.0 and 3.0 are not included in the analysis.) Alternatively, financially distressed firms are defined as those with an S\&P bond rating below "investment grade". The results based on the bond rating (not reported) are essentially the same.

${ }^{\mathrm{c}}$ Firms are identified as being either "habitual beaters" (firms that beat or meet expectations in at least $75 \%$ of the previous 12 quarters) or "sporadic beaters" (those that do not meet the criterion).

CAR is the cumulative abnormal return over the quarter beginning two days following the earliest forecast and ending the day after the earnings release. ERROR is the forecast error computed as the difference between the actual earnings and the earliest forecast for the quarter, EPS- $F_{\text {earliest }}$, standardized by price at the beginning of the quarter.

SURP is the earnings surprise computed as the difference between the actual earnings and the latest forecast for the quarter, EPS- $F_{\text {latest }}$, standardized by price at the beginning of the quarter.

DMBE is a dummy variable that takes on the value of 1 if SURP $\geqslant 0$ and 0 otherwise.

$\mathrm{DMBE}^{\text {subset }}$ is a dummy variable that takes on the value 1 if SURP $\geqslant 0$ and, in addition, the case belongs to the designated subset of the sample; otherwise

$\mathrm{DMBE}^{\text {subset }}=0$. 
In a second, related test of the expectations management hypothesis, we examine the role of the interim forecast revision in affecting the sign of the end-of-quarter earnings surprise. Specifically, we compare the observed sign of the earnings surprise with the sign of the earnings surprise that would have resulted in the absence of an interim forecast revision. As explained above, in the absence of an interim revision, the sign of the earnings surprise would be the same as the sign of the quarterly forecast error. Observing a negative forecast error that results, due to a sufficiently large downward revision, in a positive earnings surprise is thus consistent with expectations management. In the same vein, an observation with a zero or positive forecast error that ends, due to a sufficiently large upward forecast revision, with a negative earnings surprise is inconsistent with expectations management. If there is no management intervention, the proportion of observations in which the interim forecast revision offsets the sign of the earnings surprise should be identical between cases with negative errors and cases with positive errors. Our hypothesis (in alternative form), stated in terms of the difference between these proportions, is thus:

$\mathrm{H}_{7}$ : The proportion of negative forecast error cases that end with a zero or positive surprise (i.e., observations on the Down-Zero or Down-Up paths) is greater than the proportion of positive or zero forecast error cases that end with a negative surprise (i.e., observations on the Up-Down path).

\subsection{Tests of expectations management}

The results of testing $\mathrm{H}_{6}$ are provided in Table 5. The percentage of negative earnings surprises over the entire sample is $39.50 \%$, which is significantly smaller (at the $1 \%$ confidence level, using the test of proportions) than the percentage of negative forecast errors, $48.65 \%$. This result is consistent with expectations management whereby analysts' forecasts are dampened so as to increase the likelihood that the reported earnings will exceed or at least match the forecast outstanding immediately prior to the quarterly earnings announcement.

Examining the change in the frequency of negative earnings surprises across the two subperiods, 1983-1993 and 1994-1997, we find that the percentage of negative earnings surprises has declined considerably (from $47.24 \%$ to $30.68 \%$ ). While the percentage of negative forecast errors has also declined (from $55.72 \%$ to $44.34 \%$ ), the reduction in negative surprises is more dramatic as seen in the rightmost column in this table. While we offer no formal hypothesis about this shift, it appears that expectation management has become more prevalent in recent years.

The inference about the existence of expectations management is reinforced by tests of $\mathrm{H}_{7}$. As presented in Table 6, we determine the proportion of firm-quarters with a negative forecast error that end with a positive or zero surprise, and the proportion of cases with a positive or zero forecast error that end with a negative surprise. Observations that belong to the first group are more likely to result from expectations management than those in the second group. To test $\mathrm{H}_{7}$, we examine the difference between these two proportions. As the table shows, $34.80 \%$ of the 
Table 5

Relative frequency of negative forecast errors and negative earnings surprises ${ }^{\mathrm{a}}$

\begin{tabular}{llll}
\hline & $\begin{array}{l}\text { Percentage } \\
\text { of negative earnings } \\
\text { surprises (\%) }\end{array}$ & $\begin{array}{l}\text { Percentage of } \\
\text { negative forecast } \\
\text { errors }(\%)\end{array}$ & $\begin{array}{l}\text { Excess of negative } \\
\text { earnings errors over } \\
\text { negative surprise cases }(\%)\end{array}$ \\
\hline$(1)$ & $(2)$ & $(3)=(2)-(1)$ \\
\hline $\begin{array}{l}\text { All years } \\
\text { By subperiod }\end{array}$ & 39.50 & 48.65 & 9.15 \\
$1983-1993$ & 47.24 & 55.72 & 8.48 \\
$1994-1997$ & 30.68 & 44.34 & 13.66 \\
\hline
\end{tabular}

${ }^{a}$ Earnings surprise is the difference between the actual earnings and the latest forecast for the quarter, EPS $-F_{\text {latest }}$.

Forecast error is the difference between the actual earnings and the earliest forecast for the quarter, EPS $-F_{\text {earliest }}$.

The sample consists of all firms with forecast and return data over the 1983-1997 period.

firm-quarters with a negative forecast error ended, nonetheless (as a result of a sufficiently large downward revision in earnings forecasts), with a positive earnings surprise. In contrast, only $15.12 \%$ of the cases with a positive or zero forecast error ended (due to a forecast revision that "spoiled" what otherwise would have been a positive earnings surprise) with a negative earnings surprise. The difference (shown in the rightmost column), which is statistically significant, suggests the presence of expectations management and the rejection of $\mathrm{H}_{7}$. Further, this difference increased sharply over time. In the second subperiod forecast revisions are almost four times more likely to turn a negative forecast error into a positive or zero surprise than to turn a positive or zero-error forecast error into a negative surprise $(42.39 \%$ versus $11.02 \%)$. Similar to the results of testing the previous hypothesis, these results also suggest a greater propensity to manage expectations in recent years.

The above findings are consistent with revisions in earnings forecasts being managed so as to result in MBE upon the earnings announcement. In particular, downward revisions are encouraged when, in their absence, the earnings surprise is expected to be negative while upward revisions are discouraged if they might lead to a negative earnings surprise. ${ }^{15}$

\footnotetext{
${ }^{15}$ Abarbanell and Lehavy (2000) show that forecast error measures based on the comparison between $\mathrm{I} / \mathrm{B} / \mathrm{E} / \mathrm{S}$ forecasts and "actual" earnings values provided by the $\mathrm{I} / \mathrm{B} / \mathrm{E} / \mathrm{S}$ database are biased due to inconsistencies between the earnings definition used by $\mathrm{I} / \mathrm{B} / \mathrm{E} / \mathrm{S}$ and that employed by the forecasters. $\mathrm{Gu}$ and $\mathrm{Wu}$ (2000) show that analysts with a loss function proportional to the mean absolute forecast error will produce earnings forecasts that are upward (downward) biased for firms with negatively (positively) skewed earnings distributions, thus affecting the distribution of the forecast errors and earnings surprises. These biases affect the identification of the sign of both the forecast error (ERROR) and the earnings surprise (SURP) and therefore are unlikely to affect our inferences which are based on the comparison of the frequency of positive earnings surprises relative to that of positive forecast errors.
} 
Table 6

Expectations management: frequency of selected expectation paths, by period ${ }^{\mathrm{a}}$

Cases likely to be affected by expectations management (cases where the revision turns a negative forecast error into a positive or zero surprise) ${ }^{\mathrm{b}}$

Cases less likely to be affected by

expectations management (cases where

the revision turns a positive or zero-forecast Difference in

error into a negative surprise $)^{\mathrm{c}}$

proportions

\begin{tabular}{|c|c|c|c|c|c|}
\hline \multirow[b]{3}{*}{ Period } & & & \\
\hline & & $\begin{array}{l}\text { Percentage of all cases with a } \\
\text { negative forecast error }\end{array}$ & & $\begin{array}{l}\text { Percentage of all cases with a } \\
\text { positive or zero-forecast error }\end{array}$ & \\
\hline & $N$ & $(1)$ & $N$ & (2) & $(3)=(1)-(2)$ \\
\hline All years & 10,977 & $34.80 \%$ & 5,037 & $15.12 \%$ & $19.91 \% *$ \\
\hline 1983-1993 & 5,171 & $28.94 \%$ & 3,168 & $19.61 \%$ & $9.33 \% *$ \\
\hline 1994-1997 & 5,806 & $42.39 \%$ & 1,869 & $11.02 \%$ & $31.37 \% *$ \\
\hline Difference 1 & & $13.45 \% *$ & & $-8.59 \% *$ & $22.04 \% *$ \\
\hline
\end{tabular}

*Significant at the $1 \%$ level, using the test of proportions.

${ }^{a}$ Expectation paths are defined by the sign of the forecast revision and the earnings surprise. The forecast revision is the difference between the latest forecast and the earliest forecast for the quarter, $F_{\text {latest }}-F_{\text {earliest }}$. The earnings surprise is the difference between the actual earnings and the latest forecast for the quarter, EPS $-F_{\text {latest }}$. The forecast error is the difference between the actual earnings and the earliest forecast for the quarter, EPS $-F_{\text {earliest }}$.

${ }^{\mathrm{b}}$ Defined as observations on the Down-Up or Down-Zero paths.

${ }^{\mathrm{c}}$ Defined as observations on the Up-Down paths. 


\section{Association between the premium to MBE, expectations management and earnings management}

MBE may reflect the fact that firm's performance is genuinely better than expected or it could result from expectations or earnings management. If investors can trace the MBE to management intervention, they may not reward such cases with the same premium or any premium at all. Accordingly, we test an additional hypothesis (stated in alternative form):

$\mathrm{H}_{8}$ : The premium to $\mathrm{MBE}$ is smaller for cases that are more likely to be driven by expectations or earnings management.

In order to test this hypothesis relating to management intervention, we estimate regression (2), setting $\mathrm{DMBE}^{\text {subset }}$ to 1.0 alternately for $\mathrm{MBE}$ observations that are more likely to represent expectations management and for $\mathrm{MBE}$ observations that are more likely to be driven by earnings manipulation.

In line with the analysis in the previous section, MBE cases that are more likely than others to result from expectations management are identified as cases with a negative forecast error that end with a zero or positive surprise (e.g., negative forecast error cases on the Down-Zero or Down-Up paths). If investors detect expectations management and further, do not assign a premium or assign a lower premium to cases where the $\mathrm{MBE}$ is obtained through expectations management (i.e., a rejection of $\mathrm{H}_{8}$ ), $\delta_{2}$ and $\delta_{6}$ in regression (2) are expected to be negative.

A similar procedure is used to test the association between the premium to $\mathrm{MBE}$ and earnings management. We again estimate regression (2), setting $\mathrm{DMBE}^{\text {subset }}$ to 1.0 for all the cases in which the MBE is more likely to have been driven by earnings management. Such MBE cases are identified in two alternative ways, both of which are based on the identification of unexpected accruals which are assumed to be discretionary. To determine unexpected accruals, we estimate expected accruals using the two approaches described below.

The first approach for deriving expected accruals is based on a model that relates the accruals in each period to the level of activity (measured by revenues and investment in property plant and equipment) as proposed by Jones (see Jones, 1991; Dechow et al., 1995). The alternative approach for estimating expected accruals views expected accruals as consisting of working capital accruals, depreciation and amortization. ${ }^{16}$ Unexpected accruals are then measured as the abnormal level of all other accruals, which consist primarily of such items as loss and bad debt provisions (or their reversal), restructuring charges, the effect of changes in estimates, gains or losses on the sale of assets, asset write downs, the accrual and capitalization of expenses, and the deferral of revenues and their subsequent recognition. We refer to these accruals, and hence to the second approach, as "non-operating accruals". The unexpected level of these non-operating accruals reflects management's discretion

\footnotetext{
${ }^{16}$ Working capital accruals are defined as the sum of the change in accounts receivable, the change in inventory and the change in prepaid expenses, minus the sum of the change in accounts payable and the change in taxes payable.
} 
since the amount of these accruals or their timing is usually left to management's judgment. The unexpected level of the non-operating accruals is measured for a given quarter as the product of the mean over all available quarters of the ratio of non-operating accruals to total assets multiplied by the total assets at the beginning of that quarter.

To examine the effect that earnings management might have on the premium to $\mathrm{MBE}$, we adjust the reported earnings of all MBE cases by subtracting from the reported earnings the amount of unexpected accruals measured in the two alternative ways described above. We then recompute the earnings surprise (SURP) for all MBE cases to determine whether or not they still retain their MBE designation after adjusting for unexpected accruals. We test for the effect of earnings management on the premium to $\mathrm{MBE}\left(\mathrm{H}_{8}\right)$ by estimating regression (2) setting $\mathrm{DMBE}^{\text {subset }}$ to 1.0 if the above cases fail to retain their MBE designation after eliminating the unexpected accruals from the income number. If investors detect earnings management and, further, do not assign a premium, or assign a lower premium, to cases where the MBE is obtained through earnings management (i.e., a rejection of $\mathrm{H}_{8}$ ), then $\delta_{4}$ and $\delta_{6}$ are expected to be negative.

The results of the test of the association between expectations management and the premium $\left(\mathrm{H}_{8}\right)$ are provided in row 1 of Table 7 . The coefficients $\delta_{4}$ and $\delta_{6}$ are negative and mostly significant. This result suggests that the premium to MBE is significantly lower in instances in which the $\mathrm{MBE}$ is more likely to have been driven by expectations management. Overall, however, the premium to MBE in these cases still exists and is lower by only a small amount as compared with the premium to $\mathrm{MBE}$ in other cases. This is evident from the small negative coefficient for $\mathrm{DMBE}^{\text {subset }}, \delta_{4}(-0.039)$, which is the conditional intercept dummy, relative to the coefficient for DMBE, $\delta_{3}(0.075)$ the unconditional intercept dummy. A similar relationship exists between the magnitudes of the coefficients for the conditional and unconditional slope dummies ( $\delta_{6}$ is equal to -0.049 whereas $\delta_{5}=0.233$ ) These findings may either reflect investors' inability to discern expectations management or their perception that MBE is a signal about the future performance of the firm, regardless of how that signal was produced.

The second line of Table 7 shows the results from estimating regression (2) with $\mathrm{DMBE}^{\text {subset }}$ set equal to one for all MBE cases where expectations are likely to have been met or exceeded through earnings management and to zero otherwise. ${ }^{17}$ Regression (2) is estimated twice, under the two alternative ways of estimating unexpected accruals and thus of identifying MBE cases where earnings management is more likely to have occurred. Both approaches lead to the same conclusion: The

\footnotetext{
${ }^{17}$ Since earnings management can be detected through accruals, an assessment regarding the presence or absence of earnings management can be made only when the full quarterly report is publicly available. For this reason, the CAR accumulation period used to test the earnings management-related hypothesis $\left(\mathrm{H}_{8}\right)$ is extended to five days after the latest allowable filing date of the 10-Q report, or 50 days after the end of the quarter. Because the fourth quarter's results are published relatively late as part of the annual 10-K (up to 90 days after the end the fiscal year), we elected to drop the fourth quarter observations from the analysis rather than extend the accumulation period further.
} 
Table 7

Results of regression (2):

$$
\mathrm{CAR}=\delta_{0}+\delta_{1} \mathrm{ERROR}+\delta_{2} \mathrm{SURP}+\delta_{3} \mathrm{DMBE}+\delta_{4} \mathrm{DMBE}^{\text {subset }}+\delta_{5} \mathrm{DMBE} * \mathrm{SURP}+\delta_{6} \mathrm{DMBE}^{\text {subset }} * \mathrm{SURP}+\varepsilon_{\mathrm{i}, \mathrm{Q}}
$$

for cases likely to be affected by expectations management and earnings management ${ }^{\mathrm{a}}$

$(t$-statistics are provided in parentheses)

\begin{tabular}{|c|c|c|c|c|c|c|c|c|}
\hline Tested hypothesis & $\delta_{0}$ & $\delta_{1}$ & $\delta_{2}$ & $\delta_{3}$ & $\delta_{4}$ & $\delta_{5}$ & $\delta_{6}$ & $R^{2}(\%)$ \\
\hline $\begin{array}{l}\mathrm{H}_{8} \text { : The premium to } \mathrm{MBE} \text { is smaller for cases that are more likely } \\
\text { to be driven by expectations management } \\
\text { (DMBE } E^{\text {subset }}=1 \text { for } 10,977 \text { cases likely to manage expectations } \\
\text { (from Table 6); total sample consists of } 64,872 \text { cases) }\end{array}$ & $\begin{array}{r}-0.032 \\
(-30.26)\end{array}$ & $\begin{array}{r}0.415 \\
(39.68)\end{array}$ & $\begin{array}{r}0.581 \\
(10.94)\end{array}$ & $\begin{array}{r}0.075 \\
(9.62)\end{array}$ & $\begin{array}{c}-0.039 \\
(-3.57)\end{array}$ & $\begin{array}{c}0.233 \\
(2.01)\end{array}$ & $\begin{array}{c}-0.049 \\
(-1.88)\end{array}$ & 7.73 \\
\hline $\begin{array}{l}\mathrm{H}_{8} \text { : The premium to MBE is larger for cases that are less likely } \\
\text { to be driven by earnings management } \\
\text { ( } D M B E^{\text {subset }}=1 \text { for } 12,272 \text { cases likely to represent earnings } \\
\text { management where expected accruals are based on the Jones' } \\
\text { method; total sample consists of } 38,242 \text { cases with sufficient data } \\
\text { to compute expected accruals) }\end{array}$ & $\begin{array}{c}-0.029 \\
(-25.72)\end{array}$ & $\begin{array}{c}0.380 \\
(26.84)\end{array}$ & $\begin{array}{c}0.563 \\
(8.24)\end{array}$ & $\begin{array}{c}0.050 \\
(4.12)\end{array}$ & $\begin{array}{c}-0.014 \\
(-1.98)\end{array}$ & $\begin{array}{c}0.313 \\
(3.62)\end{array}$ & $\begin{array}{c}-0.020 \\
(-1.75)\end{array}$ & 6.26 \\
\hline $\begin{array}{l}\mathrm{H}_{8}: \text { The premium to MBE is larger for cases that are less likely } \\
\text { to be driven by earnings management } \\
\text { (DMBE } \\
\text { manset }=1 \text { for } 10,456 \text { cases likely to represent earnings } \\
\text { accruals definition; total sample consists of } 37,656 \text { with sufficient } \\
\text { data to compute expected accruals) }\end{array}$ & $\begin{array}{r}-0.033 \\
(-32.47)\end{array}$ & $\begin{array}{r}0.402 \\
(31.56)\end{array}$ & $\begin{array}{c}0.614 \\
(9.87)\end{array}$ & $\begin{array}{r}0.065 \\
(5.10)\end{array}$ & $\begin{array}{c}-0.025 \\
(-3.72)\end{array}$ & $\begin{array}{c}0.364 \\
(3.29)\end{array}$ & $\begin{array}{c}-0.028 \\
(-2.28)\end{array}$ & 7.46 \\
\hline
\end{tabular}

${ }^{a}$ For ERROR and SURP, the most extreme $1 \%$ of the cases at either end of the distribution each year were truncated.

$\mathrm{CAR}_{\mathrm{Q}}$ is the cumulative abnormal return over the period beginning two days following the first forecast and ending 50 days following the end of the quarter. ERROR is the forecast error computed as the difference between the actual earnings and the earliest forecast for the quarter, EPS- $F_{\text {earliest }}$, standardized by price at the beginning of the quarter.

SURP is the earnings surprise computed as the difference between the actual earnings and the latest forecast for the quarter, EPS $-F_{\text {latest }}$, standardized by price at the beginning of the quarter.

DMBE is a dummy variable that takes on the value of 1 if SURP $\geqslant 0$ and 0 otherwise.

$\mathrm{DMBE}^{\text {subset }}$ is a dummy variable that takes on the value 1 if SURP $\geqslant 0$ and the observation belongs to the designated subset of the sample; otherwise $\mathrm{DMBE}^{\text {subset }}=0$. 
premium to those $\mathrm{MBE}$ cases achieved only through sufficiently large positive unexpected accruals is significantly lower than the premium to other MBE cases.

This finding suggests that investors are capable of discerning the effect of earnings management on the earnings surprise and somewhat discount the resulting surprise. Yet, the extent of the discount is economically minor (the negative coefficients $\delta_{4}$ and $\delta_{6}$ are not only small but much smaller in absolute terms than, respectively, $\delta_{3}$ and $\delta_{5}$ ). The small discount in the premium in the cases of earnings management could be due to the difference in the power of our methodology to detect expectations management. It could also reflect the fact that investors do not complete their assessment regarding the presence of earnings management during the time period examined (i.e., within five days from the 10-Q filing date).

\section{Explanations for the premium to MBE}

\subsection{Investors' overreaction}

The incremental abnormal returns to meeting or beating analysts' expectations could also be yet another manifestation of investors' overreaction, a phenomenon documented by past research (see, for example, De Bondt and Thaler, 1987; Seyhun, 1990). For this explanation to hold, some reversal of the announcement period abnormal returns must occur in subsequent periods as the market corrects for the overreaction.

We examine the abnormal returns across the equal-error portfolios of each expectation path over the following quarter and for longer periods of one, two and three years subsequent to the earnings announcement period. ${ }^{18}$ If a reversal occurs, we would expect the paths ending with a positive earnings surprise to have significantly lower returns in these subsequent periods. The results (not presented) show no apparent reversal of the premium to MBE cases in the periods that follow the earnings announcement. In fact, there is no significant difference between the abnormal returns in subsequent periods between cases that MBE in the current period and cases that fail to do so. The notion of investors' overreaction to earnings surprises is thus not borne out by the results.

\subsection{Predictive ability of $M B E$ with respect to future performance}

An explanation for a premium to MBE consistent with investors' rationality is that the firm's success in meeting or beating its earnings estimates is informative with respect to the future performance of the company. To test this explanation, we examine the association between the incidence of MBE and the firms' performance in

\footnotetext{
${ }^{18}$ As indicated in Section 5.2, we measure abnormal returns for a period as the cumulative beta-adjusted abnormal return over the quarter. Previous research suggests that this measure provides biased values when accumulated over longer periods, such as a year (see, for example, Barber and Lyon, 1996, 1997; Kothari and Warner, 1997; Lyon et al., 1999). In calculating the longer-window abnormal returns, we correct for this bias using the procedure suggested by Lyon et al. (1999).
} 
subsequent quarters and years. Firm performance is gauged by several accounting performance measures: return-on-assets, return-on-equity, prevalence of losses, the market-to-book ratio, the profit margin, and sales and earnings growth.

The results, reported in Table 8, are consistent with the MBE having information content with respect to future performance. After controlling for the forecast error, firms that meet or beat analysts' earnings forecasts in a given quarter exhibit significantly better performance over the following two years than firms that fail to meet earnings expectations.

For cases in year $t$ with positive earnings forecast errors and positive earnings surprise, the return-on-assets in the following year $\left(\mathrm{ROA}_{t+1}\right)$, the return on equity $\left(\mathrm{ROE}_{t+1}\right)$ and the growth rate of sales is $5.7 \%, 11.0 \%$ and $24.2 \%$, respectively. In contrast, the values for these performance measures are only $2.9 \%, 1.4 \%$ and $16.7 \%$, respectively, for firms with the same forecast error that failed to meet expectations. Other performance measures in year $t+1$, such as the operating margin and the percentage of losses, show the same superior performance of firms whose quarterly earnings in year $t$ beat analysts' forecasts as compared with those who fell short of these forecasts. Cases with negative quarterly earnings forecasts show the same pattern of a better future performance for firms that meet or beat their earnings expectations. Finally, as the table shows, the better performance of the "expectation beaters" extends also to year $t+2$ although to a somewhat lesser extent. ${ }^{19}$

These results are consistent with the better performance of habitual beaters of earnings expectation documented by Kasznik and McNichols (1999). To the extent that "buy" recommendations are associated with anticipated positive firm performance, our results are also in line with the finding of a positive correlation between MBE and "buy" recommendations reported by Abarbanell and Lehavy (2000).

\section{The relation between the predictive power of MBE with respect to future performance and the extent of earnings and expectations management}

Our results thus far (as discussed in Section 8) indicate that the reward to MBE is somewhat affected by whether the MBE is genuine or whether it is likely to have been obtained through earnings or expectations management. This evidence, coupled with the finding that MBE appears to be indicative of the firm's future performance, suggests that the predictive ability of MBE may also be conditioned on whether it is a product of earnings or expectations management. To examine this, we replicate the results of Table 8 for the subset of MBE observations that are more likely to represent expectations or earnings management. The procedure to identify these cases is identical to that used in testing $\mathrm{H}_{8}$ described in Section 8 .

The results, shown in Table 9, indicate that MBE firms that are likely to have met or exceeded their earnings expectations through expectations or earnings

\footnotetext{
${ }^{19}$ Our results (not reported) also show that with respect to one measure, sales growth, the MBE firms begin to outperform those firms that subsequently fail to meet expectations in the year prior to MBE. However, there is no significant difference between the MBE and non-MBE firms on the other measures examined in the pre-MBE period.
} 
Table 8

Mean values of firm performance measures in fiscal years subsequent to the quarterly earnings surprise, by expectation path ${ }^{\mathrm{a}}$

\begin{tabular}{|c|c|c|c|c|c|c|c|c|c|c|c|c|c|c|}
\hline \multirow[b]{2}{*}{ Expectation path in fiscal year $t$} & \multicolumn{7}{|c|}{ Year $t+1$} & \multicolumn{7}{|c|}{ Year $t+2$} \\
\hline & ROA & ROE & $\begin{array}{l}\text { Freq. of } \\
\text { losses }\end{array}$ & $\begin{array}{l}\text { Sales } \\
\text { growth }\end{array}$ & $M / B$ & $\begin{array}{l}\text { Profit } \\
\text { margin }\end{array}$ & $\begin{array}{l}\text { Income } \\
\text { growth }\end{array}$ & ROA & ROE & $\begin{array}{l}\text { Freq. of } \\
\text { losses }\end{array}$ & $\begin{array}{l}\text { Sales } \\
\text { growth }\end{array}$ & $M / B$ & $\begin{array}{l}\text { Profit } \\
\text { margin }\end{array}$ & $\begin{array}{l}\text { Income } \\
\text { growth }\end{array}$ \\
\hline \multicolumn{15}{|l|}{ Positive errors } \\
\hline Up-Down & 0.029 & 0.014 & 0.167 & 0.167 & 2.460 & 0.027 & 0.089 & 0.033 & 0.029 & 0.172 & 0.125 & 2.498 & 0.026 & -0.036 \\
\hline Up-Zero & 0.038 & 0.028 & 0.138 & 0.212 & 2.735 & 0.043 & 0.141 & 0.045 & 0.043 & 0.112 & 0.180 & 2.810 & 0.039 & 0.126 \\
\hline$\bullet-U p$ & 0.057 & 0.110 & 0.108 & 0.242 & 2.871 & 0.056 & 0.420 & 0.053 & 0.104 & 0.124 & 0.201 & 2.878 & 0.051 & 0.312 \\
\hline $\begin{array}{l}\text { Difference between the } \bullet-U p \\
\text { and the Up-Down paths }\end{array}$ & $0.028^{*}$ & $0.096^{*}$ & $-0.059^{* *}$ & $0.072 *$ & $0.411^{*}$ & $0.029^{*}$ & $0.331 *$ & $0.020^{* *}$ & $0.075^{*}$ & -0.048 & $0.076^{*}$ & $0.380^{*}$ & $0.025 * *$ & $0.348^{*}$ \\
\hline \multicolumn{15}{|l|}{ Zero errors } \\
\hline Up-Down & 0.039 & 0.051 & 0.121 & 0.189 & 2.671 & 0.042 & 0.103 & 0.047 & 0.067 & 0.127 & 0.182 & 2.640 & 0.047 & 0.110 \\
\hline Zero-Zero & 0.048 & 0.092 & 0.103 & 0.227 & 2.821 & 0.064 & 0.245 & 0.056 & 0.089 & 0.114 & 0.204 & 3.126 & 0.055 & -0.054 \\
\hline Down-Up & 0.052 & 0.086 & 0.100 & 0.245 & 2.845 & 0.058 & 0.311 & 0.055 & 0.094 & 0.108 & 0.196 & 2.882 & 0.065 & 0.121 \\
\hline $\begin{array}{l}\text { Difference between the } \\
\text { Down-Up and the } \\
\text { Up-Down paths }\end{array}$ & 0.013 & $0.035^{*}$ & -0.021 & $0.056^{*}$ & 0.174 & 0.016 & $0.208^{*}$ & 0.008 & $0.027 * *$ & -0.019 & 0.014 & 0.242 & 0.016 & 0.011 \\
\hline \multicolumn{15}{|l|}{ Negative errors } \\
\hline •-Down & 0.039 & 0.042 & 0.161 & 0.124 & 2.772 & 0.040 & 0.098 & 0.036 & 0.056 & 0.176 & 0.134 & 2.520 & 0.042 & 0.083 \\
\hline Down-Zero & 0.042 & 0.083 & 0.144 & 0.210 & 2.648 & 0.068 & 0.192 & 0.044 & 0.078 & 0.152 & 0.178 & 2.680 & 0.064 & -0.061 \\
\hline Down-Up & 0.045 & 0.104 & 0.125 & 0.146 & 2.670 & 0.081 & 0.296 & 0.048 & 0.122 & 0.135 & 0.159 & 2.726 & 0.078 & -0.052 \\
\hline $\begin{array}{l}\text { Difference between the } \\
\text { Down-Up and the } \\
\text { - -Down paths }\end{array}$ & 0.006 & $0.062 *$ & -0.036 & 0.022 & -0.102 & $0.041^{*}$ & $0.198 * *$ & 0.012 & $0.066^{*}$ & $-0.041^{* *}$ & 0.025 & 0.206 & $0.036^{* *}$ & -0.135 \\
\hline
\end{tabular}

- Indicates Up, Zero and Down.

*Indicates significant difference at the 0.05 level or better (** at the 0.10 -level or better) using a one-tailed $t$-test.

${ }^{a}$ For the positive error cases, differences between the performance measure for the Up-Down and $\bullet$-Up paths are compared. For the Zero error cases, differences between the Up-Down and Down-Up paths are compared. For the negative error cases, differences between the $\bullet$-Down and Down-Up paths are compared.

ROA: Return on assets measured as net income divided by total assets profit margin: Net income divided by sales.

ROE: Return on equity measured as net income divided by book value of equity income growth: Growth in net income.

Sales growth: Growth in sales revenues.

$M / B$ : Market value of equity divided by the book value of equity. 
Table 9

Relation between the predictive power of $\mathrm{MBE}$ with respect to future performance and the extent of earnings and expectations management: mean values of future performance measures ${ }^{\mathrm{a}}$

\begin{tabular}{|c|c|c|c|c|c|c|c|c|}
\hline \multirow[b]{2}{*}{ Line } & \multirow[b]{2}{*}{ Hypothesis tests and firm groups } & \multicolumn{7}{|c|}{ Year $t+1$} \\
\hline & & ROA & ROE & $\begin{array}{l}\text { Freq. of } \\
\text { losses }\end{array}$ & $\begin{array}{l}\text { Sales } \\
\text { growth }\end{array}$ & $\mathrm{M} / \mathrm{B}$ & $\begin{array}{l}\text { Profit } \\
\text { margin }\end{array}$ & $\begin{array}{l}\text { Income } \\
\text { growth }\end{array}$ \\
\hline (1) & $\begin{array}{l}\text { Effect of expectations management on predictability } \\
\text { MBE cases likely to reflect expectations } \\
\text { management }{ }^{\mathrm{b}}(n=10,846)\end{array}$ & 0.041 & 0.053 & 0.112 & 0.181 & 2.621 & 0.070 & 0.236 \\
\hline \multirow[t]{2}{*}{ (2) } & $\begin{array}{l}\text { MBE cases not likely to reflect expectations } \\
\text { management }{ }^{\mathrm{b}}(n=5,014)\end{array}$ & 0.055 & 0.099 & 0.101 & 0.234 & 2.873 & 0.085 & 0.313 \\
\hline & Difference: Line (2)_Line (1) & $0.014^{* *}$ & $0.053^{*}$ & -0.012 & $0.043^{*}$ & $0.253^{* *}$ & $0.015 * *$ & $0.077^{*}$ \\
\hline & Effect of earnings management on predictability & & & & & & & \\
\hline (3) & $\begin{array}{l}\text { MBE cases likely to reflect earnings } \\
\text { management }^{\mathrm{c}}(n=12,272)\end{array}$ & 0.046 & 0.097 & 0.156 & 0.176 & 2.760 & 0.042 & 0.192 \\
\hline \multirow[t]{2}{*}{ (4) } & $\begin{array}{l}\text { MBE cases not likely to reflect earnings } \\
\text { management }^{c}(n=38,242)\end{array}$ & 0.049 & 0.095 & 0.114 & 0.201 & 2.846 & 0.067 & 0.236 \\
\hline & Difference: Line (4)-Line (3) & 0.003 & -0.002 & $-0.042 *$ & $0.025^{* *}$ & 0.086 & $0.025^{*}$ & $0.044^{*}$ \\
\hline (5) & Cases that failed to $\operatorname{MBE}(n=23,192)$ & 0.034 & 0.031 & 0.152 & 0.149 & 2.612 & 0.034 & 0.118 \\
\hline (6) & $\begin{array}{l}\text { Comparison between cases that failed to } \mathrm{MBE} \text { and: } \\
\text { MBE cases likely to reflect expectations management }{ }^{\mathrm{b}} \\
\text { Difference } \text { Line }\end{array}$ & $0 \Omega 07$ & $\Omega \Omega 22 * *$ & $-\Omega \Omega 4 \Omega *$ & $0022 *$ & $\Omega O \cap Q$ & $\cap \Omega 26 *$ & 月 $140 *$ \\
\hline \multirow[t]{2}{*}{ (7) } & MBE cases likely to reflect earnings management ${ }^{\mathrm{c}}$ & 0.007 & $0.022 \times \pi$ & $-0.040^{5}$ & $0.032^{*}$ & 0.009 & $0.030^{\circ}$ & $0.140^{2}$ \\
\hline & Difference: Line (3)-Line (5) & $0.012 * *$ & $0.066^{*}$ & 0.004 & $0.027 * *$ & $0.148^{*}$ & 0.008 & $0.074^{*}$ \\
\hline
\end{tabular}

*Statistically significant at the 0.05 level or better based (** indicates 0.010 level or better) on the $t$-test of equal means between the two groups.

${ }^{\text {a }}$ Performance measures are defined in Table 8.

${ }^{\mathrm{b}} \mathrm{MBE}$ cases that are likely to reflect expectations management are those associated with a negative forecast error. MBE cases that are not likely to reflect expectations management consist of all other MBE cases.

${ }^{\mathrm{c}} \mathrm{MBE}$ cases that are likely to reflect earnings management are those obtained only through "excessive" accruals in year $t$ (based on the Jones approach). MBE cases that are not likely to reflect earnings management consist of all other MBE cases. 
management generally exhibit poorer performance in the year following the MBE than firms with "genuine" MBE. All performance measures, with the exception of frequency of losses, are significantly lower in the year following the MBE for cases where the MBE is likely to have been affected by expectation management as compared to that those unlikely to be the result of expectation management. A similar pattern of inferior performance in year $t+1$ for most measures is revealed when the MBE cases that are likely to have resulted from earnings management are compared to MBE cases that are unlikely to have been driven by earnings management. The results (not shown) are almost as strong for year $t+2$, the second year after the MBE.

The results presented in lines (6) and (7) of Table 9 indicate that although the future performance of firms that "managed" their MBE is inferior to that of firms that did not manage their MBE, they still fared better than firms that failed to meet or beat their earnings expectations. This is true for most performance measures and for both of the years following the MBE year. Overall, the results suggest that MBE provides a leading indicator of the firm's future performance and that the predictive power of this indicator is only slightly diminished if it was obtained through earnings or expectations management. This result is consistent with the finding reported in Table 7 whereby the premium to MBE is only marginally related to whether it was managed. Taken together, the findings in Tables 7-9 show that market participants view, correctly, MBE as an indication of future firm performance. They are also consistent with management signaling the firm's future performance through earnings and expectations management. We do not offer an explanation for the predictive power of MBE with respect to firms' future performance nor for the finding that the premium to MBE exists also in the cases of "managed" MBE. Yet, both findings are consistent with a multi-period model where the earnings report for the last period is released when management already has partial information about the current period and where communication restrictions preclude revelation representation (see Demski, 1998).

\section{Conclusions and suggestions for further research}

The paper examines the recent phenomenon of the "expectation game" whereby companies and investors focus on the degree to which reported earnings meet or beat analysts' estimates. Anecdotal and empirical evidence, including findings provided by this paper, suggest that firms have become more successful in MBE and that this success is achieved in part by managing expectations. The evidence further shows that, after controlling for the absolute earnings performance, firms that manage to meet or beat their earnings expectations, even at the expense of an earlier dampening of those expectations, enjoy a higher return than their peers that fail to do so. While investors appear to apply some discount to MBE cases that are likely to result from expectations or earnings management, the discount is small and not significant economically. 
The finding of a premium to MBE, while explaining firms' incentive to MBE, raises questions about investor rationality. However, the reward to MBE may be justified on economic grounds since earnings surprises appear to be a reliable predictor of the firms' future performance. After controlling for the contemporaneous earnings performance, firms whose quarterly earnings releases constitute a favorable surprise show, in subsequent years, a higher growth in sales and earnings and a higher ROA and ROE than firms with the same earnings performance but with unfavorable earnings surprises. Like the premium to MBE, the predictive ability of $\mathrm{MBE}$ with respect to future firm performance depends only marginally on whether the $\mathrm{MBE}$ is genuine or whether it is produced through earnings or expectations management.

The paper's findings leave some unanswered questions, the first of which is why analysts do not correct their forecasts for what appears to be a systematic downward bias in their late-in-the-period forecasts. Or, to put it in more concrete terms, how could analysts continue to underestimate Microsoft's quarterly earnings 41 times in a row? Examination of the characteristics of "habitual beaters" of earnings forecasts may shed light on this question. Another question that merits further examination is why MBE appears to have predictive ability with respect to firms' future performance.

\section{References}

Abarbanell, J., Lehavy, R., 2000. Differences in commercial database reported earnings: implications for inferences concerning analyst forecast rationality, the association between prices and earnings, and firm reporting discretion. Working Paper, University of North Carolina, Chapel Hill, NC.

Altman, R., 1983. Corporate Financial Distress. Wiley, New York.

Ball, R., Brown, P., 1968. An empirical evaluation of accounting income numbers. Journal of Accounting Research 6, 159-178.

Barber, B.M., Lyon, J.D., 1996. Detecting abnormal operating performance: the empirical power and specification of test statistics. Journal of Financial Economics 41 (3), 359-399.

Barber, B.M., Lyon, J.D., 1997. Detecting long-run abnormal stock returns: the empirical power and specification of test statistics. Journal of Financial Economics 43 (3), 341-372.

Barefield, R.M., Comiskey, E.E., 1975. The accuracy of analysts' forecasts of earnings per share. Journal of Business Research 3 (3), 241-252.

Barth, M., Elliott, J.A., Finn, M.W., 1999. Market rewards associated with patterns of increasing earnings. Journal of Accounting Research 37 (2), 387-413.

Brown, L.D., 1997. Analyst forecasting errors: additional evidence. Financial Analysts Journal 53 (6), 81-88.

Brown, L.D., 2001. A temporal analysis of earnings surprises: profits versus losses. Journal of Accounting Research, 39 (2), 221-241.

Brown, L.D., Han, J., 1992. The impact of annual earnings announcements on convergence of beliefs. The Accounting Review 67 (4), 862-875.

Burgstahler, D., Eames, M., 1998. Management of earnings and analysts' forecasts. Working Paper, University of Washington, Seattle, WA.

DeBondt, W.F.M., Thaler, R.H., 1987. Further evidence on investor overreaction and stock market seasonality. Journal of Finance 42 (3), 557-581.

DeBondt, W.F.M., Thaler, R.H., 1990. Do security analysts overreact? American Economic Review 80 (2), 52-57. 
Dechow, P.M., Sloan, R.G., Sweeney, A.P., 1995. Detecting earnings management. The Accounting Review 70 (2), 193-225.

Degeorge, F., Patel, J., Zeckhauser, R., 1999. Earnings management to exceed thresholds. Journal of Business 72 (1), 1-33.

Demski, J., 1998. Performance measures manipulation. Contemporary Accounting Research 15 (3), 261-285.

Fox, J., 1997. Learn to play the earnings game (and wall street will love you). Fortune 135 (6), 76-80.

Francis, J., Philbrick, D., Schipper, K., 1994. Shareholder litigation and corporate disclosures. Journal of Accounting Research 32 (2), 137-164.

$\mathrm{Gu}, \mathrm{Z}$. , Wu, J., 2000. Earnings skewness and analyst forecast bias. Working Paper, University of Rochester, Rochester, NY.

Jones, J.J., 1991. Earnings management during import relief investigations. Journal of Accounting Research 29 (2), 193-228.

Kasznik, R., 1999. On the association between voluntary disclosure and earnings management. Journal of Accounting Research 37 (1), 57-81.

Kasznik, R., Lev, B., 1995. To warn or not warn: management disclosures in the face of an earnings surprise. The Accounting Review 70 (1), 113-134.

Kasznik, R., McNichols, M., 1999. Does meeting expectations matter: evidence from analyst revisions and share prices. Working Paper, Stanford University, Stanford, CA.

Kothari, S.P., Warner, J.B., 1997. Measuring long-horizon security price performance. Journal of Financial Economics 43 (3), 301-339.

Lopez, T., Rees, L., 2000. The effect of meeting analysts' forecasts and systematic positive forecast errors on the information content of unexpected earnings. Working Paper, Texas A\&M University, College Station, TX.

Lyon, J.D., Barber, B.M., Tsai, C., 1999. Improved methods for tests of long-run abnormal stock returns. Journal of Finance 54 (1), 165-201.

Matsumoto, D., 2001. Management's incentives to avoid negative earnings surprises. Working Paper, University of Washington, Seattle, WA.

McGee, S., 1997. As stock market surges ahead, "predictable" profits are driving it. The Wall Street Journal C1, 5/5/97.

Ohlson, J.A., 1995. Earnings, book values, and dividends in equity valuation. Contemporary Accounting Research 11 (2), 661-687.

Payne, J.L., Robb, S.W., 1997. Earnings management: the effect of exante earnings expectations. Working Paper, University of Oklahoma, Norman, OK.

Richardson, S.A., Teoh, S.H., Wysocki, P.D., 1999. Tracking analysts' forecasts over the annual earnings horizon: are analysts' forecasts optimistic or pessimistic? Working Paper, University of Michigan.

Seyhun, H.N., 1990. Overreaction or fundamentals: some lessons from insiders' response to the market crash of 1987. Journal of Finance 45 (5), 1363-1388.

Skinner, D.J., 1997. Earnings disclosures and stockholder lawsuits. Journal of Accounting and Economics 23 (3), 249-282.

Soffer, L.C., Thiagarajan, S.R., Walther, B.R., 2000. Earnings preannouncement strategies. Review of Accounting Studies 5 (1), 5-26.

Vickers, M., 1999. Ho-hum, another earnings surprise. Business Week M3630, 83-84.

Zarowin, P., 1989. Does the stock market overreact to corporate earnings information? Journal of Finance 44 (5), 1385-1399. 